\title{
Quantum Mechanical/Molecular Mechanical Simulation Study of the Mechanism of Hairpin Ribozyme Catalysis
}

\author{
Kwangho Nam ${ }^{\dagger}, \ddagger, \S$, Jiali Gao ${ }^{\dagger} \ddagger$, and Darrin M. York ${ }^{\dagger}$ \\ $\dagger$ Department of Chemistry and Supercomputing Institute, University of Minnesota, Minneapolis, Minnesota \\ 55455-0431 \\ $\$$ Digital Technology Center, University of Minnesota, Minneapolis, Minnesota 55455-0431
}

\begin{abstract}
The molecular mechanism of hairpin ribozyme catalysis is studied with molecular dynamics simulations using a combined quantum mechanical and molecular mechanical (QM/MM) potential with a recently developed semiempirical AM1/d-PhoT model for phosphoryl transfer reactions. Simulations are used to derive one- and two-dimensional potentials of mean force to examine specific reaction paths and assess the feasibility of proposed general acid and base mechanisms. Densityfunctional calculations of truncated active site models provide complementary insight to the simulation results. Key factors utilized by the hairpin ribozyme to enhance the rate of transphosphorylation are presented, and the roles of A38 and G8 as general acid and base catalysts are discussed. The computational results are consistent with available experimental data, provide support for a general acid/base mechanism played by functional groups on the nucleobases, and offer important insight into the ability of RNA to act as a catalyst without explicit participation by divalent metal ions.
\end{abstract}

\section{Introduction}

The hairpin ribozyme is a small RNA enzyme that catalyzes the reversible, site-specific cleavage of the phosphodiester bond of the substrate RNA strand. ${ }^{1-5}$ The chemical mechanism of the cleavage reaction involves an associative in-line attack of an activated ribose $2^{\prime}-\mathrm{OH}$ nucleophile on an adjacent phosphorus atom to create a $2^{\prime}, 3^{\prime}$-cyclic phosphate and a $5^{\prime}-\mathrm{OH}$ terminus. ${ }^{1-5}$ The ribozyme-catalyzed phosphate cleavage has a rate of $\sim 0.3 \mathrm{~min}^{-1,1,6,7}$ which represents a rate enhancement of approximately $10^{6}$-fold relative to the nonenzymatic process in aqueous solution. ${ }^{8}$ The hairpin ribozyme catalyzes the reverse ligation reaction at a rate up to an order of magnitude faster than the forward cleavage reaction. 6,7,9-11 Despite an abundance of experimental data, a detailed picture of the reaction mechanism remains unclear. Of central importance is to characterize the specific role of conserved nucleotides in the active site and assess the contributions of solvent and the electrostatic environment of the ribozyme on the reaction rate.

The hairpin ribozyme is distinct in its catalytic mechanism $2,7,12-15$ in comparison with other small self-cleaving ribozymes such as hammerhead 16,17 and hepatitis delta virus 18,19 ribozymes. For minimal hairpin ribozymes, the apparent lack of an explicit metal ion requirement for catalysis $12,14,15$ and a shallow, bell-shaped $\mathrm{pH}$-rate profile 7,15 are consistent with a general acid-base mechanism with the nucleobases playing a key role in activation of

E-mail: york@chem.umn.edu.

Present address: Department of Chemistry and Chemical Biology, Harvard University, Cambridge, MA 02138. 
the $2^{\prime}$ nucleophile and stabilization and protonation of the $5^{\prime}$ leaving group. In this scenario, the ribozyme environment would considerably perturb the $\mathrm{p} K_{\mathrm{a}}$ of one or more nucleobases. However, the nature of the ionization events of those $\mathrm{p} K_{\mathrm{a}}$-perturbed bases that affect activity cannot be unambiguously identified from kinetic data alone. As has been noted elsewhere, ${ }^{9}$ different hairpin ribozyme variants exhibit different $\mathrm{pH}$-rate behavior. For the most stable variants, catalytic activity increases linearly with $\mathrm{pH}$, consistent with a kinetic model where protonation of a functional group with apparent $\mathrm{p} K_{\mathrm{a}}$ of approximately 6 was correlated with activity. 9

Recent high-resolution X-ray crystallographic structures provide valuable insight into the active site conformation in the reactant state, ${ }^{20-22}$ transition state, and product state mimic structures. ${ }^{4}$ Comparison of these structures shows that the active site bases surrounding the cleavage site do not undergo large variation and remain poised for the in-line nucleophilic attack. The cleavage site, especially the scissile phosphate itself, undergoes greater variation as the reaction proceeds. In close proximity to the scissile phosphodiester bond in the active site, there are two key conserved nucleotides, G8 and A38, 23,24 that interact (mainly through hydrogen bonds) with the nucleophile, the leaving group, and the nonbridging phosphoryl oxygens. On the basis of the transition state mimic structure with a pentavalent vanadate ion at the scissile phosphate position, it has been suggested that A38, in protonated form, acts as a general acid in the cleavage reaction. $4,24,25$ The $\mathrm{G} 8$ nucleotide base has been implicated in the stabilization of the transition state. 4,25 This is consistent with the results from nucleotide analog interference mapping experiments. ${ }^{26,27}$ G8 and A38 are critical in catalysis: the deletion of the $\mathrm{G} 8$ base decreases the reaction rate by a factor of 350, and the deletion of the A38 base decreases the rate more than 10000 -fold relative to the wild-type control. $9,24,28,29$

One important factor is the protonation states of the scissile phosphate and other nucleotides present in the active site and their relationship to the $\mathrm{pH}$-rate profiles. Although G8, A38, and other nucleobases have been found to significantly affect the catalytic efficiency, 26,27,30,31 their specific roles in catalysis have not yet been clearly defined. Although alternative interpretations are possible, ${ }^{5,32}$ the proposal that a protonated A38 acts as a general acid in the cleavage reaction would require the $\mathrm{p} K_{\mathrm{a}}$ of $\mathrm{A} 38$ to be considerably shifted from a value of $\sim 4.3$ in solution $^{33}$ or correlated with a functional group with the apparent $\mathrm{p} K_{\mathrm{a}}$ value of $\sim 6.1$ in the hairpin ribozyme. ${ }^{9,34,35}$ If the $\mathrm{A} 38 \mathrm{p} K_{\mathrm{a}}$ remained at its value in solution, the $\mathrm{pH}$-rate profile suggests that A38 would be deprotonated over the catalytic $\mathrm{pH}$ range. $7,9,15$ Moreover, the protonation state and the role of G8 in the catalysis are also unclear. The protonation state of the reactive phosphorane intermediate and/or transition state is elusive due to the transient nature of these species in solution and in the ribozyme environment. Theoretical and reaction kinetic studies on small model compounds suggest that reactive phosphorane intermediates are most likely monoprotic ${ }^{36-40}$ in accord with their expected protonation state over the catalytic $\mathrm{pH}$ range based on estimates of oxyphosphorane $\mathrm{p} K_{\mathrm{a}}$ values in solution. ${ }^{41,42}$

In the present computational study, the main goal is to decipher the specific roles of residues G8, A38, and other nucleotide bases in hairpin ribozyme catalysis. Free energy simulations employing a combined quantum mechanical and molecular mechanical (QM/MM) potential have been applied successfully to many chemical reactions in solution ${ }^{43-48}$ and in enzymes 49,50 and are used in the present study. The high concentration of charged residues and conformational variability of RNA that can accompany the chemical catalytic steps in ribozyme catalysis present special challenges to QM/MM simulations. These conditions necessitate the use of an accurate quantum model that is sufficiently fast to allow extensive sampling of the solvent degrees of freedom and anharmonic macromolecular motions 47,49 , 51-53 to derive reliable, converged thermodynamic quantities, including often significant entropic contributions to the activation free energy barriers. ${ }^{54,55}$ Toward this end, we employ a recently developed semiempirical AM1/d-PhoT Hamiltonian model specifically designed to 
study phosphoryl transfer reactions in enzymes and ribozymes. 56 The model has been tested and demonstrated to be robust for phosphoryl transfer reactions 48,56 and sufficiently fast so as to allow long-time molecular dynamics simulations to be performed. We further examine truncated reaction model systems with density-functional theory in order to assess the reliability of the AM1/d-PhoT model and provide additional insight into mechanism.

The present paper is organized as follows. Section 2 describes the computational details of the QM/MM simulations, generation of the free energy profiles, and active site model calculations. Section 3 presents the results for the dianionic and in-line monoanionic reaction mechanisms. The remainder of the section discusses the possible roles of A38 and G8 nucleobases and the details of the mechanism that are consistent with the simulations and experiment. Section 4 concludes with a summary of the key points and identifies future research directions.

\section{Computational Details}

\subsection{Model of Hairpin Ribozyme in Solution}

The crystal structure of a transition state analog with the hairpin ribozyme (PDB code 1M5O) contains two independent (nonsymmetry-related) ribozyme structures. ${ }^{4}$ The second ribozyme structure was chosen in the present simulation study, which consists of a 92-nucleotide ribozyme strand, a 21-nucleotide substrate strand, $11 \mathrm{Ca}^{2+}$ ions, and 34 crystallographic water molecules. Three of the $\mathrm{Ca}^{2+}$ ions and the 18 crystal waters closest to the active site were considered in the simulations. The vanadate ion between the A-1 and G+1 scissile nucleotides were replaced by a phosphate group to form a trigonal bipyramidal phosphorane geometry. Nucleotides $25 \AA$ away from the scissile phosphate were removed, leaving a total of 77 nucleotides. Both the 5 '-end and the 3 '-end were terminated by a hydroxyl group.

Fully solvated MM simulations with explicit solvent under periodic boundary conditions were initially performed for the reactant state using the smooth particle mesh Ewald method 57,58 at $1 \mathrm{~atm}$ and $298 \mathrm{~K}$ to equilibrate the water molecules and ions $(0.14 \mathrm{M} \mathrm{NaCl})$. It became evident, however, that the computational effort required to treat the fully solvated system using the linear-scaling QM/MM-Ewald method ${ }^{47}$ in conjunction with the extensive QM/MM umbrella sampling that was needed to construct the 1-D and 2-D PMF profiles was not feasible with the available resources. Consequently, it was necessary to construct a considerably smaller model system for activated dynamics simulations with stochastic boundaries.

The reduced model system was constructed as follows. All nucleotide bases were modeled in their normal protonation states, except in the simulations that considered A38 to be protonated at $\mathrm{N}_{1}$ position. The positions of hydrogen atoms were determined using the HBUILD facility in the program CHARMM $^{59}$ (version c32a2). The resulting system was further solvated out to $30 \AA$ with a sphere of pre-equilibrated water molecules centered at the active site. Water molecules located beyond $25 \AA$ or within $2.5 \AA$ from any non-hydrogen atoms of the ribozyme and ions were removed. This procedure was repeated seven times by randomly rotating the water spheres to fill the potential cavities for water occupations. A total of $41 \mathrm{Na}^{+}$counterions were included. The number of $\mathrm{Na}^{+}$ions added was determined from analysis of the molecular dynamics (MD) trajectories of the fully solvated system under periodic boundary conditions, from which the number of ions within the $25 \AA$ sphere from the scissile phosphate was averaged. The final system contained 2484 RNA atoms, 56 ions, and 1625 water molecules for the system containing a neutral A38 base and monoprotic phosphorane in the active site. For completeness, we set up a total of four systems with different protonation states of A38 (neutral or protonated) and the phosphorane intermediate (monoprotic/monoanionic or unprotonated/dianionic) and two systems in which either G8 or A38 base was removed. 


\subsection{Combined QM/MM Potential}

To model the phosphate cleavage reaction, a combined QM/MM potential $51,52,60$ was used in all calculations. The system was partitioned into a QM region, constituting the active site and modeled with the AM1/d-PhoT Hamiltonian, 56 and a MM region, containing the rest of the system modeled with the allatom CHARMM27 nucleic acid force field 61,62 and TIP3P water model. ${ }^{63}$ The AM1/d-PhoT model ${ }^{56}$ is a reparametrized AM1/d model for phosphoryl transfer reactions in enzymes and ribozymes based on model reactions in a new database of quantum calculations for RNA catalysis $(Q C R N A)^{40,64}$ and has recently been applied to simulations of the full length hammerhead ribozyme. ${ }^{65}$ Simulations were performed using the CHARMM software package ${ }^{59}$ (version c32a2) interfaced with the MNDO97 program. ${ }^{66}$ The QM subsystem consists of the scissile phosphodiester group and parts of the A-1 and G+1 ribose rings. The bonded QM/MM interaction (to treat division of the $\mathrm{QM}$ and $\mathrm{MM}$ subsystem across a covalent bond) was modeled using the generalized hybrid orbital (GHO) method 67 that was used at the following bond positions (asterisk indicates the $\mathrm{GHO}$ atom): * ${ }^{*} 1^{\prime}-\mathrm{C} 2$ ' and * $\mathrm{C} 4{ }^{\prime}-\mathrm{C} 3{ }^{\prime}$ bonds in $\mathrm{A}-1,{ }^{*} \mathrm{C} 4{ }^{\prime}-\mathrm{C} 5$ ' bond in $\mathrm{G}+1$, and in simulations with $\mathrm{A} 38$ protonated, the ${ }^{*} \mathrm{C} 1{ }^{\prime}-\mathrm{N} 9$ bond in $\mathrm{A} 38$. When the G8 base was included in the QM subsystem, the QM/MM boundary was set at the * ${ }^{*} 1^{\prime}-\mathrm{N} 9$ bond in G8. The nonbonded QM/MM van der Waals interaction was modeled with a Lennard-Jones potential with parameters for the QM subsystem optimized such that the QM/MM interactions in TIP3P water clusters reproduce corresponding density-functional results (see Supporting Information).

\subsection{Molecular Dynamics Simulations}

The starting systems were initially relaxed by restrained minimizations to alleviate high-energy contacts without significantly altering the active site structure. Then, stochastic boundary molecular dynamics simulations (SBMD) ${ }^{68,69}$ were carried out to further equilibrate the system and to sample the configuration space in the free energy simulations. In SBMD, the aqueous environment was represented by a $25 \AA$ sphere of water molecules centered at the geometric center of the active site, defined as the center of QM subsystem. A solvent boundary potential 68 was applied to mimic the effect of external solvent and to act as a confining potential to prevent diffusion of water outside the sphere. Nucleotides more than $25 \AA$ away from the center of the sphere were held fixed during the simulations. The nucleotides in the region from 21 to $25 \AA$ from the center were harmonically restrained to the initial X-ray crystal positions with force constants determined from the crystallographic B-factor values according to the relation

$$
f_{i}=\frac{3 k_{\mathrm{B}} T}{\left\langle\Delta r_{i}^{2}\right\rangle}=3 k_{\mathrm{B}} T \frac{8 \pi^{2}}{3 B_{i}}
$$

where $f_{i}$ is the restoring harmonic force constant on atom $i, k_{\mathrm{B}}$ is Boltzmann's constant, $T$ is temperature, and $B_{i}$ is the isotropic crystallographic B-factor for the heavy (non-hydrogen) atom $i$. The force constants thus derived were multiplied by a scaling factor that varies linearly from 0 to 1 between 21 and $25 \AA .{ }^{69}$ In the MD simulations, the atoms within a sphere of 21 $\AA$ from the center were treated by Newtonian dynamics, and the atoms in the radial range between 21 and $25 \AA$ were treated by Langevin dynamics, which also serves as a thermal bath to maintain constant temperature during the simulation. Atomic positions were propagated using the leapfrog Verlet algorithm with $1 \mathrm{fs}$ integration time. ${ }^{70}$ Initially, the systems were slowly heated from 8 to $298 \mathrm{~K}$ over $11.6 \mathrm{ps}$ and subsequently equilibrated at $298 \mathrm{~K}$ for $100 \mathrm{ps}$. During the equilibration, harmonic restraints (force constant of $500.0 \mathrm{kcal} / \mathrm{mol}-\AA^{2}$ ) were used for the nucleophilic $\mathrm{O}_{2^{\prime}} \mathrm{P}$ and leaving group $\mathrm{P}^{-\mathrm{O}_{5}}{ }^{\prime}$ bonds to ensure the integrity of the transition state phosphorane geometry. Throughout MD simulations, the nonbonded electrostatic and van der Waals interactions were evaluated without truncation (no-cutoff), and all bond lengths 
involving hydrogen atoms in the MM subsystem were constrained using the SHAKE algorithm.

71 During the umbrella sampling MD simulations, harmonic restraining potentials with a force constant of $12.0 \mathrm{kcal} / \mathrm{mol}-\AA_{2}$ were applied to the $\mathrm{Na}^{+}$ions in the radial range between 21 and $25 \AA$ at their equilibrated positions in accord with the restraints applied to other nucleotide atoms in that range.

\subsection{Free Energy Simulations}

The potentials of mean force (PMFs) for the ribozyme catalyzed cleavage reaction were determined using umbrella sampling ${ }^{72}$ SBMD simulations and the QM/MM potential without electrostatic or van der Waals cutoff as described above. In the present study, the PMF is represented as a function of one or two reaction coordinates. In the former, the reaction coordinate is defined as

$$
\zeta_{1}=R_{\mathrm{P}-\mathrm{O}_{5^{\prime}}}-R_{\mathrm{P}-\mathrm{O}_{2^{\prime}}},
$$

where $R_{\mathrm{P}-\mathrm{O}_{5^{\prime}}}$ and $R_{{\mathrm{P}-\mathrm{O}_{2}}^{\prime}}$ are the distances of the ribosyl $\mathrm{O}_{5^{\prime}}$ and $\mathrm{O}_{5^{\prime}}$ atoms from the $\mathrm{P}$ atom, respectively. When two reaction coordinates are considered, the first reaction coordinate $\zeta_{1}$ is the same as that of eq 2 , and the second reaction coordinate $\zeta_{2}$ is defined as

$$
\zeta_{2}=R_{\text {Donor- }-\mathrm{H}}-R_{\text {Acceptor-H }}
$$

where $R_{\text {Donor-H }}$ and $R_{\text {Acceptor-H }}$ are the distances of the proton to be transferred from the donor and to the acceptor atom, respectively. The one-dimensional PMF models the free energy change for the nucleophilic substitution reaction itself, whereas the two-dimensional PMF addresses the question of concerted versus stepwise mechanism involving both substitution and proton transfer in a general acid-base catalysis. A series of umbrella sampling MD simulations were carried out to span the entire range of the reaction coordinate(s) from the reactant to the products. To enhance sampling efficiency, a harmonic restraining potential was applied with a force constant ranging between 30.0 and $110.0 \mathrm{kcal} / \mathrm{mol}-\AA^{2}$ based on the shape of the PMF profile for each system. This ensures sufficient overlap of the probability distribution with neighboring windows. Each umbrella sampling window was equilibrated for $17 \mathrm{ps}$ followed by 30-50 ps of configuration sampling with data collected at every dynamics integration step. The weighted histogram analysis method (WHAM) ${ }^{73,74}$ was used to combine the sampled configurations to compute the unbiased PMFs as a function of the reaction coordinate(s). Further details for individual simulations are provided in the Supporting Information.

We have carried out 8 independent 2-D PMF simulations for the nucleophilic substitution step and the exocyclic cleavage step with either the nonbridging oxygen $\left(\mathrm{O}_{1 \mathrm{P}}\right.$ or $\left.\mathrm{O}_{2 \mathrm{P}}\right)$ acting as a proton acceptor from $\mathrm{O}_{2}$, nucleophile and with protonated and unprotonated $\mathrm{A} 38$ base, respectively. However, the free energy values obtained from the 2-D profiles can only be considered as an estimation for the barrier height, and a more rigorous evaluation of the contribution from the two reaction coordinates is required. ${ }^{75,76} \mathrm{~A} 1-\mathrm{D}$ reaction coordinate was constructed as a linear combination of the two reaction coordinates in the 2-D PMF, which corresponds to the minimum free energy path on the 2-D surface. Free energy simulations along this 1-D reaction coordinate were then performed for $100 \mathrm{ps}$ to construct the 1-D PMF profile. ${ }^{77}$ To estimate the errors of computed PMFs, the $100 \mathrm{ps}$ of sampled data were partitioned into 20 ps segments and PMFs were separately computed for each 20 ps data set. From the resulting PMF profiles, the standard deviation was obtained and used as a statistical error estimate. We have also tested the effects of G8 and A38 base deletion by repeating 1-D PMF simulations with a hydrogen atom replacing G8 and A38 base, respectively. 


\subsection{Active Site Model Calculations}

To further validate the results using the AM1/d-PhoT model at the rate-determining exocyclic cleavage transition state, a series of density functional calculations was carried out on truncated active site models. The active site model for the dianionic reaction ( 24 atoms) consists of a nucleophilic ribose ring with $\mathrm{O}_{2^{\prime}}$ deprotonated, a scissile phosphate, and a leaving ethyl group; the activation energy at the transition state was taken from the QCRNA database. ${ }^{40}$ The active site model for the in-line monoanionic reaction (49 atoms) consists of two ribose rings for A-1 and $\mathrm{G}+1$ but with the bases removed, the scissile phosphate, and the G8 base with N9 atom capped by a hydrogen atom. For the A38 mediated monoanionic reaction, the model ( 65 atoms) includes an additional protonated A38 base. Except for the dianionic reaction that was taken directly from the QCRNA database, the starting geometry for each model reaction was the equilibrated geometry of the intermediate state followed by energy minimizations at the semiempirical AM1/d-PhoT QM/MM level. The geometry optimizations were carried out at the reactant state and the exocyclic cleavage transition state. All structures were optimized in the gas phase with Kohn-Sham density functional theory (DFT) methods using the hybrid exchange functional of Becke ${ }^{78,79}$ and the Lee-Yang-Parr correlation functional ${ }^{80}$ (B3LYP) at the $6-31+\mathrm{G}(\mathrm{d})$ basis set level. Vibrational frequency calculations were performed to confirm the correct topological nature of the minima and transition states. To mimic the restraints applied by the hairpin ribozyme, several atoms were kept frozen through all geometry optimizations; the frozen atoms were $\mathrm{O}_{4^{\prime}}$ of A-1, $\mathrm{C}_{3^{\prime}}$ of $\mathrm{G}+1, \mathrm{~N} 9$ of A38 and $\mathrm{G} 8$ base, respectively, which are reasonably separated from the scissile phosphate. Electronic energies were further refined by single-point energy calculations using $6-31++\mathrm{G}(\mathrm{d}, \mathrm{p})$ basis set. The same procedure was followed at the semiempirical AM1/d-PhoT level to assess the reliability of the model. All DFT calculations were performed with the GAUSSIAN03 suite of programs, 81 and AM1/d-PhoT model calculations were carried out using the MNDO97 program. ${ }^{66}$ The DFT-optimized geometries and energies are provided in the Supporting Information.

\section{Results and Discussion}

This section presents the results from free energy simulations and discusses their implications into the mechanism of the hairpin ribozyme catalyzed self-cleaving reaction. Several mechanisms are explored to provide insight into the role of different conserved active site residues, in particular, G8 and A38, which have been suggested to be involved as general acidbase catalysts. Three general mechanisms are considered: (1) a dianionic mechanism whereby it is assumed that the nucleophile has been previously activated and that the leaving group is unprotonated, (2) a monoanionic mechanism whereby a nonbridging phosphoryl oxygen acts as the general base and acid, and (3) an A38(+) mediated mechanism where the cleavage step is facilitated by proton donation from a nearby adenine (A38) residue protonated at the N1 position. These mechanisms are illustrated in Scheme 1-3. Thermodynamic and kinetic results from the free energy simulations are summarized in Table 1, and the averages for key structural parameters are listed in Tables 2 and 3. A more detailed decomposition of the nucleobases and solvent contributions in stabilizing the transition states and reactive intermediates are provided in Table 4 and in the Supporting Information. The 2-D PMF profiles for the in-line monoanionic mechanism are shown in Figure 1. The structures of the phosphorane intermediate and transition state in the active site are illustrated in Figures 2 and 3. The 1-D PMF profiles are compared in Figure 4.

\subsection{Dianionic Reaction}

The dianionic mechanism (Scheme 1) considered here assumes that the deprotonation of nucleophilic $\mathrm{O}_{2}$ and the protonation of leaving group $\mathrm{O}_{5^{\prime}}$ occur sequentially and are not ratecontrolling and therefore can be treated independently from the transphosphorylation reaction step. We consider here only the transphosphorylation step where the 2 ' hydroxyl nucleophile 
has already been activated (for example by a hydroxide ion coordinated to an active site base) and the leaving 5' alkoxide group has not yet been protonated (for example from the solvent or a nucleobase) after the exocyclic cleavage. As shown by recent biochemical studies that explore the $\mathrm{pH}$-rate profiles for unmodified and chemically modified hairpin ribozyme at different temperatures, ${ }^{9}$ the dianionic mechanism is not likely to be the most physiologically relevant. Nevertheless, characterization of this mechanism provides useful reference for comparison and elucidation of the key factors that govern catalytic proficiency.

1-D PMF Profiles-Free energy simulations have been carried out on the transphosphorylation step using a total of 27 separate simulations that span the entire reaction. The reaction coordinate is defined by eq 2 . The reaction proceeds via a single transition state corresponding to the exocyclic cleavage (Scheme 1) and the computed barrier height is 15.6 $\mathrm{kcal} / \mathrm{mol}$ (Table 1). This can be compared with a barrier of $30.1 \mathrm{kcal} / \mathrm{mol}$ computed for the uncatalyzed reaction estimated from a nonenzymatic model for transesterification proceeding through a dianionic methyl ethylene phosphorane transition state in water. ${ }^{48}$ The ribozyme environment decreases the barrier by $14.5 \mathrm{kcal} / \mathrm{mol}$ for the dianionic mechanism.

Density-Functional Calculations-The density-functional result for the dianionic in-line mechanism is in close agreement with that of the AM1/d-PhoT model. The adiabatic DFT barrier for the dianionic model reaction is $28.8 \mathrm{kcal} / \mathrm{mol}$ in the gas phase, whereas the corresponding AM1/d-PhoT result is $29.5 \mathrm{kcal} / \mathrm{mol}$. If this $0.7 \mathrm{kcal} / \mathrm{mol}$ difference is applied as a correction to the AM1/d-PhoT barrier from the 1-D PMF profile, the barrier decreases from 15.6 to $14.9 \mathrm{kcal} / \mathrm{mol}$ (Table 1). For the dianionic reaction mechanisms, the AM1/d-PhoT model is in good accord with the DFT results. 56

$\mathrm{p} K_{\mathrm{a}}$ of the 2' $\mathrm{OH}-$ It remains to obtain an estimate of the free energy required to activate the nucleophile, for example, from a $\mathrm{p} K_{\mathrm{a}}$ calculation using a QM/MM free energy perturbation approach $^{82}$ or quantum/continuum calculations. ${ }^{41,83} \mathrm{~A}$ theoretical prediction of the $\mathrm{p} K_{\mathrm{a}}$ of the $2^{\prime} \mathrm{OH}$ requires careful calibration of the theoretical model and quantum corrections, and is a topic of future work. Nonetheless, a rough estimate of the free energy required to activate $2^{\prime} \mathrm{OH}$ can be obtained from the $\mathrm{p} K_{\mathrm{a}}$ of a secondary alcohol such as 2-propanol $\left(\mathrm{p} K_{\mathrm{a}} 17.1^{33}\right)$. If the $\mathrm{p} K_{\mathrm{a}}$ shift due to the ribozyme environment is neglected (a considerable approximation), this results in a $13.7 \mathrm{kcal} / \mathrm{mol}$ free energy requirement at $300 \mathrm{~K}$ to activate the nucleophile at neutral $\mathrm{pH}$, shifting the rate-controlling barrier from 15.6 to $29.3 \mathrm{kcal} / \mathrm{mol}$. This estimated barrier is too high in comparison to the experimental estimate of $20-21 \mathrm{kcal} / \mathrm{mol},{ }^{2,7,9,84}$ which is to be expected because RNA cleavage is thought to proceed via a phosphorane monoanion. $36,42,85$ Nonetheless, it is of interest to note that the ribozyme environment considerably lowers the activation barrier for the dianionic mechanism relative to the uncatalyzed reaction and likely contributes to the catalytic proficiency.

\subsection{In-Line Monoanionic Reaction}

In the in-line monoanionic mechanism (Scheme 2), nonbridging oxygens play a dual role as a proton acceptor in the nucleophilic attack by the $\mathrm{O}_{2^{\prime}}$ atom, forming a monoprotic phosphorane intermediate, and a proton donor to the leaving group $\left(\mathrm{O}_{5^{\prime}}\right)$ in the exocyclic cleavage step. Because the two nonbridging oxygens, $\mathrm{O}_{1 \mathrm{P}}$ and $\mathrm{O}_{2 \mathrm{P}}$ (proR and proS O, respectively), experience different electrostatic environments, we have tested both as potential acid/base catalysts. The free energy simulations have been divided into two separate steps: (1) the nucleophilic attack along with the proton transfer from $\mathrm{O}_{2}$ onto the nonbridging oxygen and (2) the exocyclic cleavage of the $\mathrm{P}^{-\mathrm{O}_{5}}{ }^{\prime}$ bond with the transfer of proton on the nonbridging oxygen to the $\mathrm{O}_{5^{\prime}}$ atom. To provide insight into the extent to which the nucleophilic attack/ cleavage and proton transfers are concerted or stepwise, 2-D umbrella sampling calculations were performed. Each step (nucleophilic attack or exocyclic cleavage) requires two umbrella 
sampling reaction coordinates defined by eqs 2 and 3 . For the $\mathrm{O}_{1 \mathrm{P}}$ pathway, for example, a total of 212 and 183 separate simulations (windows) have been carried out for the nucleophilic attack and cleavage steps, respectively. Each simulation window was performed for $17 \mathrm{ps}$ of equilibration, followed by $50 \mathrm{ps}$ of sampling, resulting in a total of $26 \mathrm{~ns}$ of MD simulation. The same procedure was repeated for the $\mathrm{O}_{2 \mathrm{P}}$ pathway.

2-D PMF Profile for the $O_{1 P}$ Pathway-Figure $1 \mathrm{~A}$ presents the two-dimensional PMF profile for the hairpin ribozyme transesterification reaction, in which the nonbridging $\mathrm{O}_{1 \mathrm{P}}$ atom plays the role of both general base and general acid. The first reaction step of the $\mathrm{O}_{1 \mathrm{P}}$ pathway (the left half of the 2-D PMF in Figure 1A) is almost stepwise: the proton on the $\mathrm{O}_{2^{\prime}}$ hydroxyl group is first transferred to $\mathrm{O}_{1 \mathrm{P}}$ followed by the nucleophilic attack of $\mathrm{O}_{2^{\prime}}$ at phosphorus. The computed free energy barrier from Figure $1 \mathrm{~A}$ is about $15 \mathrm{kcal} / \mathrm{mol}$ for the $\mathrm{O}_{2}{ }_{2}$ proton-transfer step, which is slightly higher than the barrier for the nucleophilic attack (Table 1). The free energy of the phosphorane intermediate relative to the reactant state is about $13 \mathrm{kcal} / \mathrm{mol}$. The second reaction step (the right half of the 2-D PMF in Figure 1A) exhibits only one transition state, corresponding to the exocyclic cleavage of the $\mathrm{P}^{-\mathrm{O}_{5}}$ bond followed by barrierless proton transfer from $\mathrm{O}_{1 \mathrm{P}}$ to the $\mathrm{O}_{5}$, leaving group. The free energy barrier for the exocyclic cleavage is about $12 \mathrm{kcal} / \mathrm{mol}$ from the intermediate state (Figure 1A). The overall free energy barrier from the 2-D profile for the cleavage reaction is $25 \mathrm{kcal} / \mathrm{mol}$ (Table 1).

2-D PMF Profile for the $\mathrm{O}_{2 \mathrm{P}}$ Pathway-The reaction path via the nonbridging $\mathrm{O}_{2 \mathrm{P}}$ oxygen shows a similar profile (Figure 1B). The first step of the $\mathrm{O}_{2 \mathrm{P}}$ pathway (the left half of the 2-D PMF in Figure 1B) indicates the proton transfer has a lower barrier than that of the $\mathrm{O}_{1 \mathrm{P}}$ pathway by about $3 \mathrm{kcal} / \mathrm{mol}$. The barrier for the nucleophilic attack to the phosphorus center is about $14 \mathrm{kcal} / \mathrm{mol}$ relative to the reactant state (Table 1 ). The intermediate state is also about $13 \mathrm{kcal} /$ mol higher than the reactant state. The results suggest that the proton transfer to the $\mathrm{O}_{2} \mathrm{P}$ position is favorable relative to the proton transfer to the $\mathrm{O}_{1 \mathrm{P}}$ oxygen by $\sim 3 \mathrm{kcal} / \mathrm{mol}$. This arises from the differential stabilization of accumulated charge on the nonbridging oxygens at the scissile phosphate, mainly through specific hydrogen bonds to conserved residues such as G8, A9, and A38, and water solvation in the asymmetric ribozyme active site (Figure $2 \mathrm{~A}$ and B). ${ }^{21,22 \text {, }}$

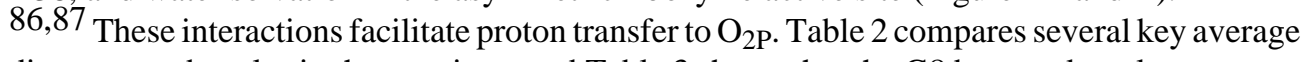
distances and angles in the reactions, and Table 3 shows that the G8 base makes close contact with $\mathrm{O}_{2^{\prime}}$ at the monoprotic phosphorane intermediate in the $\mathrm{O}_{2 \mathrm{P}}$ pathway.

The barrier heights for the exocyclic cleavage step differ between the $\mathrm{O}_{1 \mathrm{P}}$ and $\mathrm{O}_{2 \mathrm{P}}$ reaction pathways, despite the overall similar shape of their PMF profiles (Figure 1). The barrier height from the intermediate to the transition state is about $8 \mathrm{kcal} / \mathrm{mol}$ in the $\mathrm{O}_{2 \mathrm{P}}$ pathway, which is about $4 \mathrm{kcal} / \mathrm{mol}$ lower than that for the $\mathrm{O}_{1 \mathrm{P}}$ pathway. The overall barrier for the entire cleavage step is approximately $21 \mathrm{kcal} / \mathrm{mol}$ based on the 2-D PMF profile (Table 1 ). The difference in the barrier heights can be rationalized by the corresponding transition state geometries (Figure $3 \mathrm{~A}$ and $\mathrm{B}$ ). From Figure 3B, the $\mathrm{H}-\mathrm{O}_{2} \mathrm{P}$ bond is aligned adjacent and antiparallel to the elongated $\mathrm{P}^{-} \mathrm{O}_{5}$, bond. These dipoles interact favorably to provide additional stabilization on the polarization of $\mathrm{P}_{-} \mathrm{O}_{5^{\prime}}$ bond. The 2-D PMF plot for the $\mathrm{O}_{2 \mathrm{P}}$ pathway (Figure $1 \mathrm{~B}$ ) exhibits a more gradual rise in free energy around $1.0 \AA$ along the proton-transfer reaction coordinate $\left(\zeta_{2}\right)$ relative to that of the $\mathrm{O}_{1 \mathrm{P}}$ pathway.

The transition state for the in-line monoanionic $\mathrm{O}_{2}$ p pathway is preferentially stabilized by solvent compared with the $\mathrm{O}_{1 \mathrm{P}}$ pathway (Table 4). This is due to the orientations of the $\mathrm{O}_{5^{\prime}}$ leaving group and unprotonated nonbridging oxygens that share a formal -1 charge in the ratecontrolling transition state. In the $\mathrm{O}_{2 \mathrm{P}}$ pathway, solvation is more effective due to the relative orientations of these groups, which leave them more solvent exposed (see Figure 3B): in the first solvation sphere (out to $5.0 \AA$ ), water stabilizes the $\mathrm{O}_{1 \mathrm{P}}$ and $\mathrm{O}_{2 \mathrm{P}}$ pathways by -18.4 and $-25.9 \mathrm{kcal} / \mathrm{mol}$, respectively. The preferential solvent stabilization of the rate-controlling 
$\mathrm{TS}_{\mathrm{Cl}}$ transition state for the $\mathrm{O}_{2 \mathrm{P}}$ pathway relative to that of the $\mathrm{O}_{1 \mathrm{P}}$ pathway is also observed for the $\mathrm{INT}_{2}$ phosphorane intermediate, and underscores the importance of solvation in discerning specific reaction pathways.

1-D PMF Profiles-It is worthwhile to briefly clarify the differences in the free energy values obtained from the 2-D PMF and 1-D PMF profiles on the in-line monoanionic mechanism. The 2-D PMF is a function of two degrees of freedom, and the 1-D PMF is a function along the minimum free energy path in the 2-D surface. Separate free energy simulations were performed to sample all other degrees of freedom except that corresponding to this minimum path, resulting in a variationally optimized transition state along the reaction coordinate. The effects from the second degree of freedom in the 2-D PMF cannot be assumed negligible, especially when there is a shallow and broad basin in the 2-D PMF such as that in the reactant and product states, which makes significant entropic contribution. In the in-line monoanionic $\mathrm{O}_{1 \mathrm{P}}$ pathway, the effects are not large in the reactant state but are considerable in the product state (Figure 1A), whereas in the $\mathrm{O}_{2}$ p pathway the effects are qualitatively reversed (Table 1). The differences between the free energy values derived from the 1-D PMF quantitatively refine, but do not alter, the general conclusions about the hairpin mechanism based on the 2-D PMF profiles.

Density-Functional Calculations-For the in-line monoanionic mechanism, the DFT results indicate that the AM1/d-PhoT model has similar differences for the $\mathrm{O}_{1 \mathrm{P}}$ and $\mathrm{O}_{2 \mathrm{P}}$ pathways ( 2.3 and $2.5 \mathrm{kcal} / \mathrm{mol}$ of error, respectively). The DFT-corrected barrier for the exocyclic cleavage step is $25.0 \mathrm{kcal} / \mathrm{mol}$ in the $\mathrm{O}_{1 \mathrm{P}}$ pathway and $20.5 \mathrm{kcal} / \mathrm{mol}$ in the $\mathrm{O}_{2 \mathrm{P}}$ pathway, respectively (Table 1). The hairpin ribozyme stabilizes the intermediate state by more than $15 \mathrm{kcal} / \mathrm{mol}$ compared to the transphosphorylation reaction of methyl ethylene phosphate (MEP) in water, 56 a simple model for the uncatalyzed reaction. There are several hydrogen bonds that play important roles in the stabilization of the intermediate and transition states, in particular, functional groups on G8 and A9 bases, as well as solvent molecules (Table 3 and also see the Supporting Information).

\subsection{Role of A38 Nucleobase}

Ferré-D'Amaré and co-workers proposed on the basis of crystallographic analyses that the protonated A38 nucleobase may act as a general acid to donate a proton to the $\mathrm{O}_{5^{\prime}}$ leaving group. ${ }^{4,25}$ The involvement of A38 nucleotide base on catalysis is further supported by Fedor and co-workers, who found that the reaction rate decreases more than $10^{4}$-fold after A38 base is removed. ${ }^{9}$ To address the proposal that $\mathrm{A} 38$ acts as a general acid in the exocyclic cleavage, two different simulations are carried out with $\mathrm{A} 38$ protonated at the $\mathrm{N}_{1}$ position, henceforth designated A38(+).

1-D PMF Profiles-The first set of simulations follows analogously the reaction coordinate for the in-line monoanionic mechanism, but with a protonated A38 base (Scheme 3). The 1-D PMF profiles are compared in Figure 4. The initial step is the proton transfer from $\mathrm{O}_{2}$, to the nonbridging oxygen, followed by nucleophilic attack of $\mathrm{O}_{2^{\prime}}$ at the $\mathrm{P}$ atom, forming the monoprotic phosphorane intermediate as described in Section 3.2. The A38(+) base forms hydrogen bonds with the nonbridging $\mathrm{O}_{1 \mathrm{P}}$ oxygen and the $\mathrm{O}_{5^{\prime}}$ leaving group. In the second step, the proton on $\mathrm{N}_{1}$ of $\mathrm{A} 38(+)$ is transferred to the leaving group along with the exocyclic cleavage of the $\mathrm{P}^{-} \mathrm{O}_{5}$ bond, whereas the proton from the nucleophile remains on the nonbridging oxygen.

For the nucleophilic attack step in the A38(+) mediated mechanism, the proton transfer from the nucleophile favors the $\mathrm{O}_{2 \mathrm{P}}$ by $7.2 \mathrm{kcal} / \mathrm{mol}$ over the $\mathrm{O}_{1 \mathrm{P}}$ position, and the rate-controlling cleavage step by $2.2 \mathrm{kcal} / \mathrm{mol}$ from the AM1/d-PhoT model (Table 1 ). The presence of proton 
on $\mathrm{O}_{1 \mathrm{P}}$ hinders the hydrogen bond with the exocyclic amine group on $\mathrm{A} 38$, whereas this hydrogen bond is strengthened in the $\mathrm{O}_{2 \mathrm{P}}$ pathway. In the $\mathrm{O}_{2 \mathrm{P}}$ pathway, the accumulation of negative charge on $\mathrm{O}_{1 \mathrm{P}}$ after the protonation of $\mathrm{O}_{2 \mathrm{P}}$ further strengthens the interaction with protonated A38 base (Table 4).

The formation of a strong hydrogen bond with the A38(+) weakens the interaction of the phosphate group with G8 (the average interaction energies of selected nucleotide bases are provided in the Supporting Information). Comparison of intermediate geometries shows that the A38(+) base pulls the phosphate group closer and its distance to G8 concomitantly lengthens (Figure $2 \mathrm{C}$ and $\mathrm{D}$ ). This distorts the orientation of phosphate toward the $\mathrm{A} 38(+)$ base and hinders nucleophilic attack of $\mathrm{O}_{2^{\prime}}$ on the $\mathrm{P}$ atom. In particular, the phosphorane geometry from the $\mathrm{A} 38(+)$ mediated $\mathrm{O}_{2 \mathrm{P}}$ pathway is partially pseudo-rotated to maintain the interaction with G8 nucleobase, having an $\mathrm{O}_{2^{\prime}}-\mathrm{P}_{-} \mathrm{O}_{5^{\prime}}$ angle of 134 degrees (Table 2 and Figure 2D). The protonated $\mathrm{A} 38$ base is a better proton donor than the $\mathrm{O}_{2 \mathrm{P}}$ nonbridging oxygen of the phosphorane intermediate, and the A38(+) mediated mechanism has an earlier transition state than that of the in-line monoanionic mechanism. The computed barrier heights from the two A38(+) mediated pathways are 24.4 and $22.2 \mathrm{kcal} / \mathrm{mol}$ for $\mathrm{O}_{1 \mathrm{P}}$ and $\mathrm{O}_{2 \mathrm{P}}$ atoms acting as the general base from the AM1/d-PhoT model, respectively.

Density-Functional Calculations-The AM1/d-PhoT truncated active site model has an activation energy for the rate-controlling exocyclic cleavage step that is $8 \mathrm{kcal} / \mathrm{mol}$ higher than the corresponding density-function result for both the $\mathrm{O}_{1 \mathrm{P}}$ and $\mathrm{O}_{2 \mathrm{P}}$ pathways. If this difference is applied as a DFT correction, the barrier height for the $\mathrm{TS}_{\mathrm{Cl}}$ step becomes 16.4 and $14.4 \mathrm{kcal} /$ mol for the $\mathrm{O}_{1 \mathrm{P}}$ and $\mathrm{O}_{2 \mathrm{P}}$ pathways, respectively (Table 1). However, consideration must be taken into account for the free energy required to protonate the A38 nucleobase to quantify the true activation barrier. A rough estimate of the free energy required to protonate A38 at neutral $\mathrm{pH}$ can be made based on the $\mathrm{p} K_{\mathrm{a}}$ of 4.3 of a free adenine base, ${ }^{33}$ leading to an increase in barrier height by $3.7 \mathrm{kcal} / \mathrm{mol}$ at $300 \mathrm{~K}$. The shifted and DFT corrected barriers become 20.1 and $18.1 \mathrm{kcal} / \mathrm{mol}$ for the $\mathrm{O}_{1 \mathrm{P}}$ and $\mathrm{O}_{2} \mathrm{P}$ pathways, respectively (Table 1 ). In each pathway, the proton from $\mathrm{A} 38(+)$ is transferred without barrier immediately following the transition state of the exocyclic cleavage step.

\subsection{Role of G8 Nucleobase}

Until now, the focus is on the nucleophilic step along with the in-line proton transfer from $\mathrm{O}_{2^{\prime}}$ onto the nonbridging oxygen. Several experiments implicate the involvement of G8 in the catalytic step, $20,21,28-30,32$ although it has not yet been possible to establish unambiguously its precise role as a general base. The energetic contribution of the G8 base from the current simulations indicates that G8 contributes to the stabilization of the transition states and the phosphorane intermediate by providing stabilizing hydrogen bond interactions. However, it is possible that $\mathrm{G} 8$ acts as a general base to activate the $\mathrm{O}_{2^{\prime}}$ nucleophile. This section aims at providing insight into the role of the G8 nucleobase, under the assumption that the active form of G8 is neutral. This is reasonable because the negatively charged active site would not prefer to have an extra negative charge near the scissile phosphate. It is plausible that tautomerization between $\mathrm{N}_{1}$ and $\mathrm{O}_{6}$ on the guanine base ${ }^{30}$ is important for activity. In this case, $\mathrm{N}_{1}$ accepts a proton from $\mathrm{O}_{2^{\prime}}$ prior to the nucleophilic attack and becomes positively charged, which can further stabilize the negative charges on the scissile phosphate. The energetic difference between these two forms in the gas phase is small; the computed adiabatic energy difference between the two tautomeric forms is $1.1 \mathrm{kcal} / \mathrm{mol}$ from B3LYP/6-311++G(3df,-2p) and 0.6 $\mathrm{kcal} / \mathrm{mol}$ from the AM1/d-PhoT model, where the tautomer with proton on $\mathrm{N}_{1}$ has lower energy. Therefore, the proton affinities of two functional groups are similar in the gas phase. 88 
To test this possibility in the ribozyme, we have carried out free energy simulations to compute the free energy difference between the two tautomeric forms. The resulting free energy difference is $19.1 \mathrm{kcal} / \mathrm{mol}$ in the active site of the hairpin ribozyme. Although it is possible that the calculations are biased by the starting X-ray structure, the large free energy difference essentially rules out the possibility that the tautomeric form of G8 acts as the general base in the nucleophilic attack step. The present result supports the importance of a proton located on $\mathrm{N}_{1}$ of G8 as well as the exocyclic amine group, as proposed by Pinard et al. ${ }^{30}$ In addition, it is consistent with the recent X-ray crystallographic structures with several G8 variants suggesting that the base G8 primarily plays a structural role in the ribozyme reaction. ${ }^{21}$

\subsection{Comparison with Experiment}

A main mechanistic question is to identify the general acid and base and the associated protonation state of the reactive intermediates. The present work provides important insight into these questions. Although we cannot rule out the possibility of a water acting as a specific base, the nonbridging oxygens are a plausible candidate as a general base to activate the $\mathrm{O}_{2}$ nucleophile. The G8 base, on the other hand, while providing important hydrogen bond stabilization in the reaction, is not a viable candidate as a general base for the mechanisms that were explored in the present study. The present results show that $\mathrm{O}_{2 \mathrm{P}}$ is the preferred general base that accepts a proton from $\mathrm{O}_{2^{\prime}}$ with a computed barrier of $10.5 \mathrm{kcal} / \mathrm{mol}$ for the protontransfer process in the in-line monoanionic mechanism (Figure 1B). Kinetic experiments revealed that RNA cleavage reactions are most preferred through a phosphorane monoanion charge state, ${ }^{36,42,85}$ but direct measurement of $\mathrm{p} K_{\mathrm{a}}$ values for phosphoranes is difficult due to their transient nature. Proposed values from experiment and theory are in the range of 6.5-11.0 and of 11.3-15.0 for the first and second ionizations, respectively. ${ }^{36,41,42}$ As the reaction proceeds to the phosphorane intermediate, the $\mathrm{p} K_{\mathrm{a}}$ is shifted to a higher value, and the nonbridging oxygens increase their proton affinity. If the reaction is characterized by a dianionic mechanism, in which a base other than the nonbridging oxygens extracts the proton from $\mathrm{O}_{2}$, prior to the nucleophilic attack, ${ }^{36}$ the lifetime of the dianionic phosphorane (likely a true transition state) may be insufficient to undergo protonation whereby the reaction would proceed directly to the product. Alternative mechanisms are also possible. One aspect that has not yet been thoroughly addressed is the possible chemical role played by solvent networks in the active site, for example in mediating proton transfers. ${ }^{89}$ Trapped water molecules have been observed to interact with nonbridging oxygens in the active site of hairpin ribozyme, ${ }^{87}$ but these waters are readily exchangeable with bulk solvent and exhibit considerable configurational variation. A detailed study of the role of solvent networks in the chemical steps of acid/base catalysis is nontrivial and will be a focus of future work.

The in-line monoanionic mechanism explains the mechanism for protonation of the phosphorane intermediate, and identifies the nonbridging phosphoryl oxygen as a plausible candidate to act as the general base. This mechanism implies a relatively minor chemical role of the A38 nucleobase in the catalysis and is different from the mechanisms proposed from structural $^{4,25}$ and kinetic analysis. ${ }^{9}$ One finding from molecular dynamics free energy simulations in the $\mathrm{O}_{1 \mathrm{P}}$ pathway is that the neutral A38 nucleobase prefers to base stack with A40 and retracts slightly from the scissile phosphate and the leaving group. The retraction of A38 is less pronounced for the $\mathrm{O}_{2 \mathrm{P}}$ pathway where a weak hydrogen bond with the $\mathrm{O}_{1 \mathrm{P}}$ atom is retained (Table 3).

The reduction of reaction rates by the removal of $\mathrm{G} 8$ and $\mathrm{A} 38$ base $9,28,29$ suggests the involvement of those bases in the catalysis. On the other hand, the current simulation study supports the mechanism of G8 playing structural role by providing hydrogen bonds to the scissile phosphate, and A38 being a general acid in the exocyclic cleavage step. Although this does not imply a disagreement, to verify the agreement of the simulations with the experiments, 
two free energy simulations were carried out, in particular, along the in-line monoanionic $\mathrm{O}_{2 \mathrm{P}}$ pathway, each of which has either removed G8 or A38 base, respectively. The results are presented in Table 1. After the DFT-correction, the A38 base deletion raises the barrier by 6.7 $\mathrm{kcal} / \mathrm{mol}$ (or $3.0 \mathrm{kcal} / \mathrm{mol}$ with $\mathrm{p} K_{\mathrm{a}}$ correction for A38) with respect to the A38(+) mediated $\mathrm{O}_{2 \mathrm{P}}$ pathway. The increase in barrier height is consistent with the reduction of reaction rate more than $10^{4}$-fold. Similarly, the deletion of G8 base raises the reaction barrier by $3.6 \mathrm{kcal} /$ mol in the inline monoanionic $\mathrm{O}_{2 \mathrm{P}}$ pathway. It is likely that the strong interaction of $\mathrm{G} 8$ base with the scissile phosphate is not fully compensated by water molecules occupying the space of removed G8 base (see the Supporting Information for the snapshots at the $\mathrm{INT}_{2}$ state).

The present simulations reveal a possible role of the nonbridging oxygen as a general acid catalyst in the absence of the $\mathrm{A} 38$ base. ${ }^{9}$ On the other hand, when A38 is protonated, the current results support the proposal that it is the general acid in catalysis, in addition to its role in hydrogen bonding and base stacking interactions. $4,9,24,25$ The computed activation barriers for the $\mathrm{A} 38(+)$ mediated mechanism do not include the free energy contribution required to protonate A38, whereas an estimate of its contribution is provided in Table 1 based on the $\mathrm{p} K_{\mathrm{a}}$ of a free adenine base. Determination of the $\mathrm{p} K_{\mathrm{a}}$ shift of A38 in the ribozyme environment via quantum chemical calculation or NMR experiments can be valuable to aid in the resolution of the kinetic ambiguity inherent in the analysis of $\mathrm{pH}$-rate profiles. Additional calculations to reproduce kinetic and thermodynamic properties of mutations that designed to probe the active site architecture of the hairpin ribozyme ${ }^{24}$ can further contribute to formulating a consistent mechanism based on theory and experiment.

\section{Conclusion}

This work presents a theoretical study of the hairpin ribozyme self-cleavage mechanism using molecular simulations and a combined QM/MM potential, making use of the recently developed AM1/d-PhoT Hamiltonian. The latter has been developed against high level theoretical and experimental results. The present study further demonstrates that the AM1/dPhoT potential is a reliable Hamiltonian in comparison with density functional results for the hairpin ribozyme reactions. The computed barrier height relative to that in solution is consistent with experimental results. The enhancement of the reaction rate by the ribozyme is due to the stabilization of the monoprotic phosphorane intermediate and the transition state by the ribozyme. The simulation results offer a plausible alternative to the notion that catalysis is by a general acid/base mechanism with the direct involvement of active site nucleotide bases. The experimentally identified nucleobases, including G8, A9, and A38, are intimately involved in the stabilization of phosphorane intermediates. The present results provide evidence that the role of the G8 nucleobase in the catalysis is mainly structural, which is unlikely to play the role of a general base to activate $\mathrm{O}_{2}$, nucleophile. The role of the A38 nucleobase as general acid has not been fully resolved, although the nonbridging phosphoryl oxygen is shown to be a feasible candidate to play the role of general base in abstracting a proton prior to or concerted with nucleophilic attack. The nucleotide bases, phosphate, and water molecules in the active site provide an extensive hydrogen bond network, stabilizing the transition state and increasing the reaction rate by more than a million-fold relative to the uncatalyzed reaction in solution.

\section{Supplementary Material}

Refer to Web version on PubMed Central for supplementary material.

\section{Acknowledgment}

This work was partially supported by grants from the National Institutes of Health (GM62248 to D.Y. and GM46736 to J.G.), the University of Minnesota Biomedical Informatics and Computational Biology program (D.Y.), and the 
Office of Naval Research (ONR) under grant number N00012-05-01-0538. Computational resources were provided by the Minnesota Supercomputing Institute.

\section{References}

(1). Walter NG, Burke JM. Curr. Opin. Chem. Biol 1998;2:24-30. [PubMed: 9667918]

(2). Fedor MJ. J. Mol. Biol 2000;297(2):269-291. [PubMed: 10715200]

(3). Doherty EA, Doudna JA. Annu. Rev. Biophys. Biomol. Struct 2001;30:457-475. [PubMed: 11441810]

(4). Rupert PB, Massey AP, Sigurdsson ST, Ferré-D’Amaré AR. Science 2002;298:1421-1424. [PubMed: 12376595]

(5). Bevilacqua PC. Biochemistry 2003;42:2259-2265. [PubMed: 12600192]

(6). Hegg LA, Fedor MJ. Biochemistry 1995;34:15813-15828. [PubMed: 7495813]

(7). Nesbitt SM, Erlacher HA, Fedor MJ. J. Mol. Biol 1999;289:1009-1024. [PubMed: 10047478]

(8). Li Y, Breaker RR. J. Am. Chem. Soc 1999;121:5364-5372.

(9). Kuzmin YI, Costa CPD, Cottrell JW, Fedor MJ. J. Mol. Biol 2005;349:989-1010. [PubMed: 15907933]

(10). Nahas MK, Wilson TJ, Hohng S, Jarvie K, Lilley DMJ, Ha T. Nat. Struct. Mol. Biol 2004;11:11071113. [PubMed: 15475966]

(11). Liu S, Bokinsky G, Walter NG, Zhuang X. Proc. Natl. Acad. Sci. U.S.A 2007;104(31):1263412639. [PubMed: 17496145]

(12). Hampel A, Cowan JA. Chem. Biol 1997;4:513-517. [PubMed: 9263639]

(13). Chowrira BM, Burke JM. Biochemistry 1991;30:8518-8522. [PubMed: 1909564]

(14). Young KJ, Gill F, Grasby JA. Nucleic Acids Res 1997;25:3760-3766. [PubMed: 9380495]

(15). Nesbitt S, Hegg LA, Fedor MJ. Chem. Biol 1997;4:619-630. [PubMed: 9281529]

(16). Scott WG, Murray JB, Arnold JRP, Stoddard BL, Klug A. Science 1996;274:2065-2069. [PubMed: 8953035]

(17). Scott WG. Q. Rev. Biophys 1999;32:241-294. [PubMed: 11194566]

(18). Shih, I.-h.; Been, M. Biochemistry 2000;39:9055-9066. [PubMed: 10924098]

(19). Shih, I.-h.; Been, MD. Annu. Rev. Biochem 2002;71:887-917. [PubMed: 12045114]

(20). Rupert PB, Ferré-D’Amaré AR. Nature 2001;410:780-786. [PubMed: 11298439]

(21). Salter J, Krucinska J, Alam S, Grum-Tokars V, Wedekind JE. Biochemistry 2006;45:686-700. [PubMed: 16411744]

(22). Torelli AT, Krucinska J, Wedekind JE. RNA 2007;13:1052-1070. [PubMed: 17488874]

(23). Butcher SE, Burke JM. Biochemistry 1994;33:992-999. [PubMed: 8305446]

(24). Cottrell JW, Kuzmin YI, Fedor MJ. J. Biol. Chem 2007;282:13498-13507. [PubMed: 17351263]

(25). Ferré-D’Amaré AR. Biopolymers 2004;73:71-78. [PubMed: 14691941]

(26). Ryder SP, Strobel SA. Nucleic Acids Res 2002;30:1287-1291. [PubMed: 11884625]

(27). Ryder SP, Oyelere AK, Padilla JL, Klostermeier D, Millar DP, Strobel SA. RNA 2001;7:14541463. [PubMed: 11680850]

(28). Lebruska LL, Kuzmine II, Fedor MJ. Chem. Biol 2002;9:465-473. [PubMed: 11983335]

(29). Kuzmin YI, Da Costa CP, Fedor MJ. J. Mol. Biol 2004;340:233-251. [PubMed: 15201049]

(30). Pinard R, Hampel KJ, Heckman JE, Lambert D, Chan PA, Major F, Burke JM. EMBO J 2001;20:6434-6442. [PubMed: 11707414]

(31). Thomas JM, Perrin DM. J. Am. Chem. Soc 2006;128:16540-16545. [PubMed: 17177403]

(32). Wilson TJ, Ouellet J, Zhao Z.-y. Harusawa S, Araki L, Kurihara T, Lille DM. RNA 2006;12:980987. [PubMed: 16601203]

(33). Lide, DR., editor. CRC Handbook of Chemistry and Physics. Vol. 83rd ed.. CRC Press LLC; Boca Raton, FL: 2003.

(34). Tang CL, Alexov E, Pyle AM, Honig B. J. Mol. Biol 2007;366:1475-1496. [PubMed: 17223134]

(35). Wilson TJ, Nahas M, Araki L, Harusawa S, Ha T, Lilley DM. Blood Cell. Mol. Dis 2007;38:8-14. 
(36). Perreault DM, Anslyn EV. Angew. Chem., Int. Ed 1997;36:432-450.

(37). Liu Y, Gregersen BA, Lopez X, York DM. J. Phys. Chem. B 2005;109:19987-20003. [PubMed: 16853584]

(38). Lopez X, Dejaegere A, Leclerc F, York DM, Karplus M. J. Phys. Chem. B 2006;110:11525-11539. [PubMed: 16771429]

(39). Liu Y, Gregersen BA, Hengge A, York DM. Biochemistry 2006;45:10043-10053. [PubMed: 16906762]

(40). Giese TJ, Gregersen BA, Liu Y, Nam K, Mayaan E, Moser A, Range K, Nieto Faza O, Silva Lopez C, Rodriguez de Lera A, Schaftenaar G, Lopez X, Lee T, Karypis G, York DM. J. Mol. Graph. Model 2006;25:423-433. [PubMed: 16580853]

(41). Lopez X, Schaefer M, Dejaegere A, Karplus M. J. Am. Chem. Soc 2002;124(18):5010-5018. [PubMed: 11982365]

(42). Davies J, Doltsinis N, Kirby A, Roussev C, Sprik M. J. Am. Chem. Soc 2002;124:6594-6599. [PubMed: 12047179]

(43). Gao J. Acc. Chem. Res 1996;29:298-305.

(44). Gao J, Garcia-Viloca M, Poulsen TD, Mo Y. Adv. Phys. Org. Chem 2003;38:161-181.

(45). Gregersen BA, Lopez X, York DM. J. Am. Chem. Soc 2003;125:7178-7179. [PubMed: 12797782]

(46). Gregersen BA, Lopez X, York DM. J. Am. Chem. Soc 2004;126:7504-7513. [PubMed: 15198597]

(47). Nam K, Gao J, York DM. J. Chem. Theory Comput 2005;1(1):2-13.

(48). Nam, K.; Gao, J.; York, DM. Large Scale MD, Meso, and Nanoscale Modeling. Ross, R., editor. Oxford University Press; New York: 2006. ACS Symposium Series

(49). Garcia-Viloca M, Gao J, Karplus M, Truhlar DG. Science 2004;303:186-195. [PubMed: 14716003]

(50). Gao J, Ma S, Major D, Nam K, Pu J, Truhlar D. Chem. Rev 2006;106(8):3188-3209. [PubMed: 16895324]

(51). Field MJ, Bash PA, Karplus M. J. Comput. Chem 1990;11:700-733.

(52). Gao J. Rev. Comput. Chem 1995;7:119-185.

(53). Gao J. Curr. Opin. Struc. Biol 2003;13:184-192.

(54). Villà J, Štrajbi M, Glennon TM, Sham YY, Chu ZT, Warshel A. Proc. Natl. Acad. Sci. U.S.A 2000;97(22):11899-11904. [PubMed: 11050223]

(55). Štrajbl M, Sham YY, Villà J, Chu Z-T, Warshel A. J. Phys. Chem. B 2000;104:4578-4584.

(56). Nam K, Cui Q, Gao J, York DM. J. Chem. Theory Comput 2007;3:486-504.

(57). Essmann U, Perera L, Berkowitz ML, Darden T, Hsing L, Pedersen LG. J. Chem. Phys 1995;103 (19):8577-8593.

(58). Sagui C, Darden TA. Annu. Rev. Biophys. Biomol. Struct 1999;28:155-179. [PubMed: 10410799]

(59). Brooks BR, Bruccoleri RE, Olafson BD, States DJ, Swaminathan S, Karplus M. J. Comput. Chem 1983;4:187-217.

(60). Warshel A, Levitt M. J. Mol. Biol 1976;103:227-249. [PubMed: 985660]

(61). Foloppe N, MacKerell AD Jr. J. Comput. Chem 2000;21:86-104.

(62). MacKerell AD Jr. Banavali NK. J. Comput. Chem 2000;21:105-120.

(63). Jorgensen WL, Chandrasekhar J, Madura JD, Impey RW, Klein ML. J. Chem. Phys 1983;79:926935.

(64). QCRNA. http://theory.chem.umn.edu/Database/QCRNA

(65). Lee T-S, Silva-Lopez C, Martick M, Scott WG, York DM. J. Chem. Theory Comput 2007;3:325327. [PubMed: 19079784]

(66). Thiel, W. MNDO97, Version 5.0. University of Zurich; 1998.

(67). Gao J, Amara P, Alhambra C, Field MJ. J. Phys. Chem. A 1998;102:4714-4721.

(68). Brooks CL III, Karplus M. J. Chem. Phys 1983;79:6312-6325.

(69). Brooks CL III, Brunger A, Karplus M. Biopolymers 1985;24:843-865. [PubMed: 2410050]

(70). Allen, M.; Tildesley, D. Computer Simulation of Liquids. Oxford University Press; Oxford: 1987.

(71). Ryckaert JP, Ciccotti G, Berendsen HJC. J. Comput. Phys 1977;23:327-341.

(72). Torrie GM, Valleau JP. J. Comput. Phys 1977;23:187-199. 
(73). Kumar S, Bouzida D, Swendsen R, Kollman P, Rosenberg J. J. Comput. Chem 1992;13:1011-1021.

(74). Rajamani R, Naidoo KJ, Gao J. J. Comput. Chem 2003;24:1775-1781. [PubMed: 12964196]

(75). Truhlar DG, Garrett BC. Acc. Chem. Res 1980;13:440-448.

(76). Schenter GK, Garrett BC, Truhlar DG. J. Chem. Phys 2003;119(12):5828-5833.

(77). To test the effects of electrostatic solvation outside of $25 \AA$ water sphere on the computed barrier heights, we have repeated QM/MM 1-D umbrella sampling simulations along with COSMOreaction field (seeGregersen BA, York DM. J. Phys. Chem. B 2005;109:536. [PubMed: 16851046]) for the in-line monoanionic $\mathrm{O}_{2} \mathrm{P}$ pathway and $\mathrm{A} 38(+)$ mediated $\mathrm{O}_{1 \mathrm{P}}$ pathway, respectively. The computed barrier heights agree with the results without reaction field within $1-2 \mathrm{kcal} / \mathrm{mol}$.

(78). Becke AD. Phys. Rev. A 1988;38:3098-3100. [PubMed: 9900728]

(79). Becke AD. J. Chem. Phys 1993;98(7):5648-5652.

(80). Lee C, Yang W, Parr RG. Phys. Rev. B 1988;37:785-789.

(81). Frisch, MJ., et al. Gaussian 03, revision C.02. Gaussian, Inc.; Wallingford, CT: 2004.

(82). Riccardi D, Schaefer P, Cui Q. J. Phys. Chem. B 2005;109:17715-17733. [PubMed: 16853267]

(83). Lyne PD, Karplus M. J. Am. Chem. Soc 2000;122:166-167.

(84). Fedor MJ. Biochemistry 1999;38:11040-11050. [PubMed: 10460159]

(85). Breslow R. Proc. Natl. Acad. Sci. U.S.A 1993;90:1208-1211. [PubMed: 7679493]

(86). Park H, Lee S. J. Chem. Theory Comput 2006;2:858-862.

(87). Rhodes MM, Réblová K, Sponer J, Walter NG. Proc. Natl. Acad. Sci. U.S.A 2006;103:1338013385. [PubMed: 16938834]

(88). Gorb L, Podolyan Y, Leszczynski J, Siebrand W, Fernández-Ramos A, Smedarchina Z. Biopolymers 2002;61:77-83. [PubMed: 11891630]

(89). Gerratana B, Sowa GA, Cleland WW. J. Am. Chem. Soc 2000;122(51):12615-12621. 


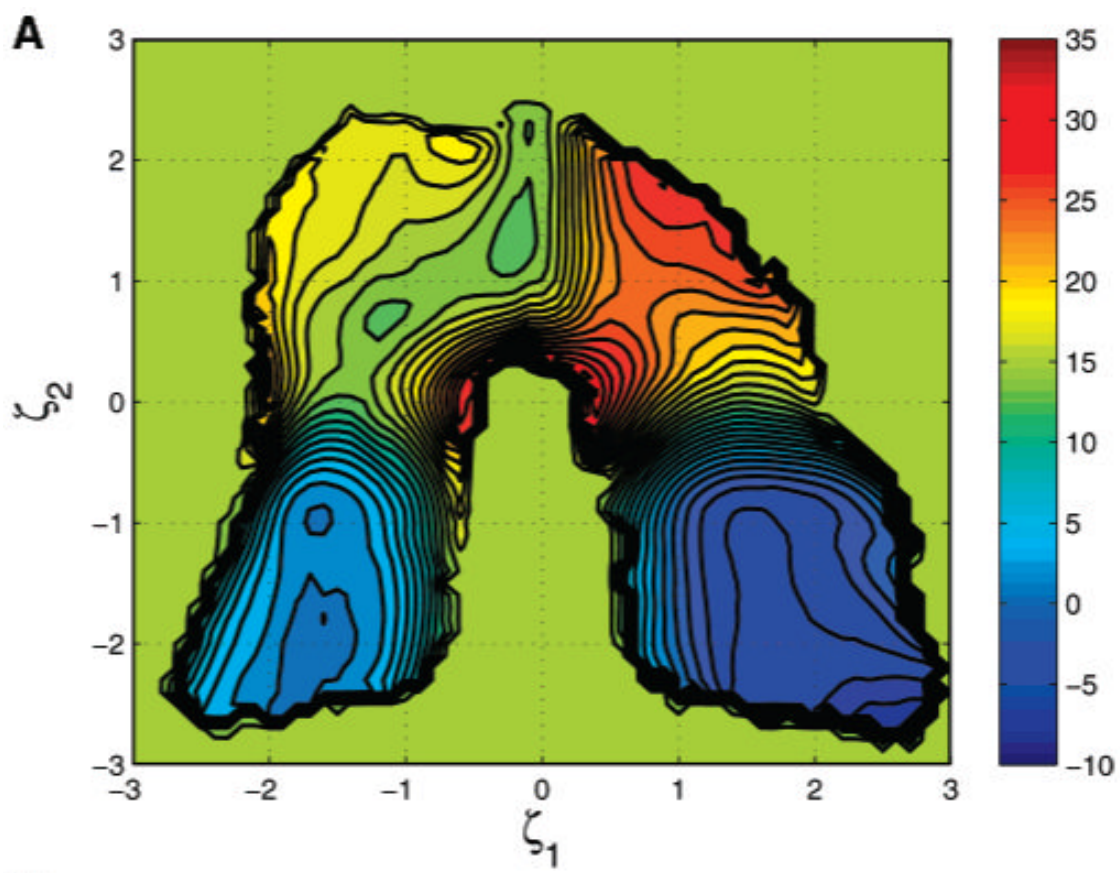

B

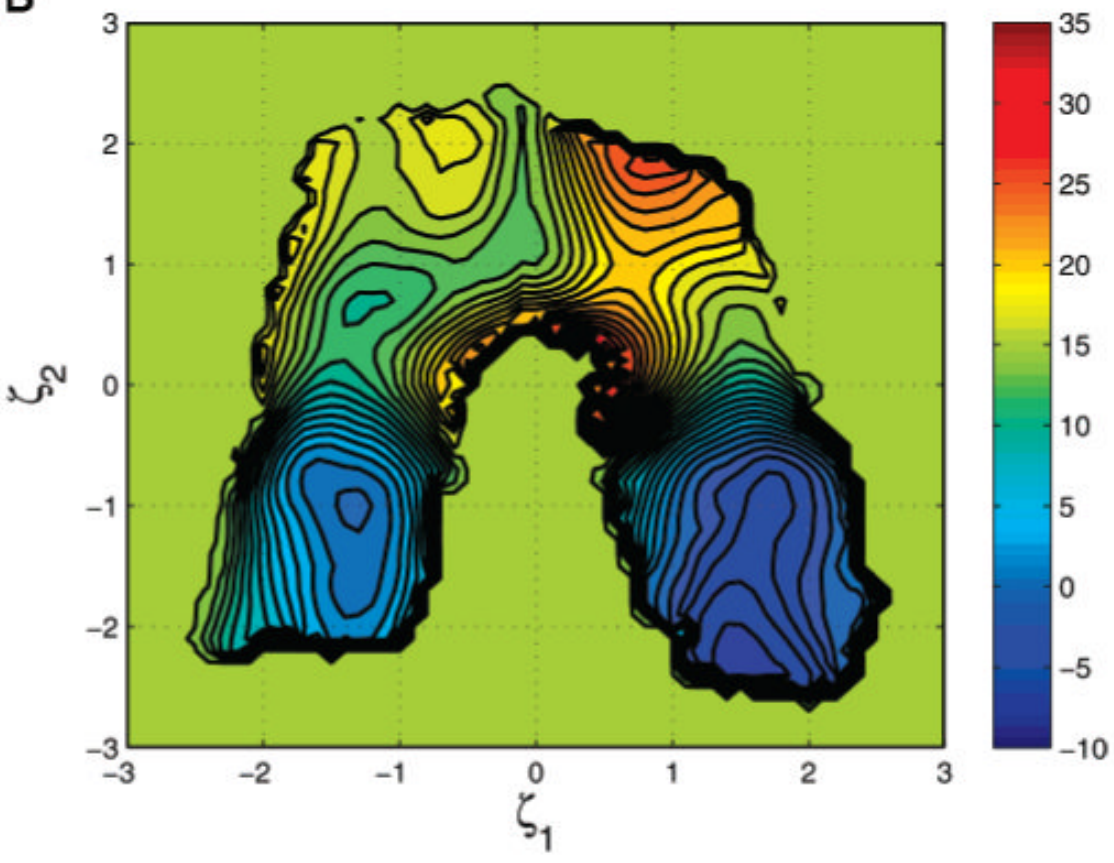

Figure 1.

Computed two-dimensional potentials of mean force for the in-line monoanionic mechanism, accompanied by (A) the $\mathrm{O}_{1 \mathrm{P}}$ proton-transfer pathway, and (B) the $\mathrm{O}_{2 \mathrm{P}}$ proton-transfer pathway. The abscissa defines the reaction coordinate for the nucleophilic substitution, $\zeta_{1}=R\left(\mathrm{P}_{-} \mathrm{O}_{5^{\prime}}\right)$ $R\left(\mathrm{P}-\mathrm{O}_{2^{\prime}}\right)$, and the ordinate depicts the reaction coordinate for the proton-transfer process, $\zeta_{2}$. The left-hand side region, where $\zeta_{1}<0.0 \AA$, corresponds to the coordinate $\zeta_{2}=R\left(\mathrm{O}_{2^{\prime}}-H_{2^{\prime}}\right)$ $R\left(\mathrm{O}_{\mathrm{NB}}-\mathrm{H}_{2^{\prime}}\right)$, whereas in the right-hand side, where $\zeta_{1}>0.0 \AA$, the ordinate is defined by $R$ $\left(\mathrm{O}_{5^{\prime}}-\mathrm{H}_{2^{\prime}}\right)-R\left(\mathrm{O}_{\mathrm{NB}}-\mathrm{H}_{2^{\prime}}\right) . \mathrm{O}_{\mathrm{NB}}$ is for the $\mathrm{O}_{1 \mathrm{P}}$ proton transfer in $(\mathrm{A})$, and for the $\mathrm{O}_{2 \mathrm{P}}$ proton transfer in (B). Free energies are given in $\mathrm{kcal} / \mathrm{mol}$. 
A

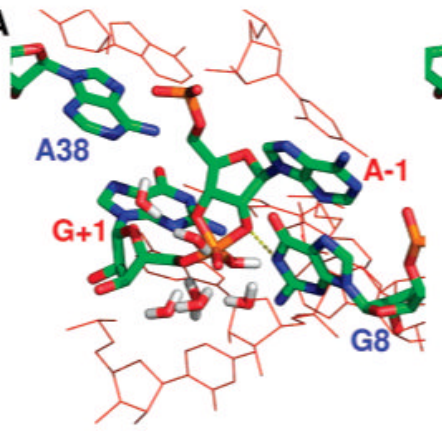

C

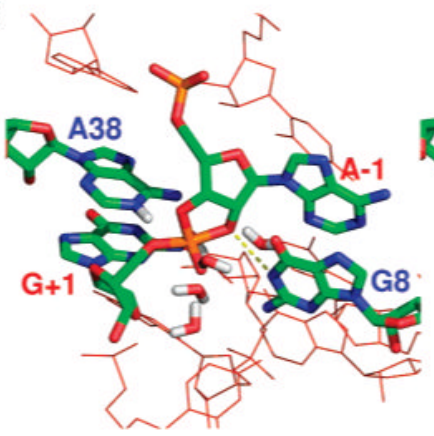

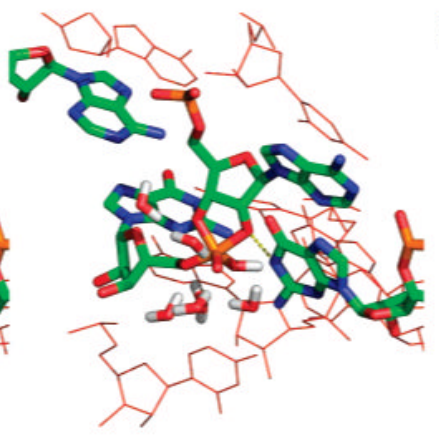

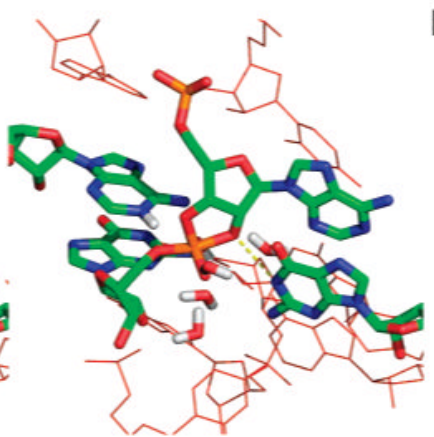

B

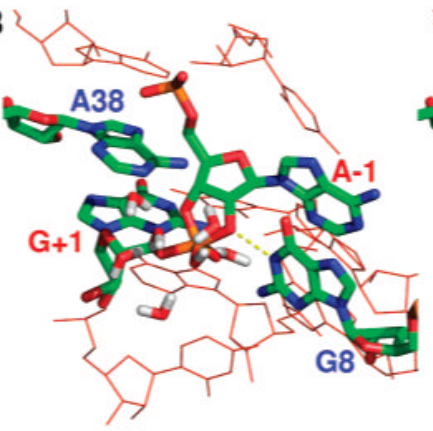

D

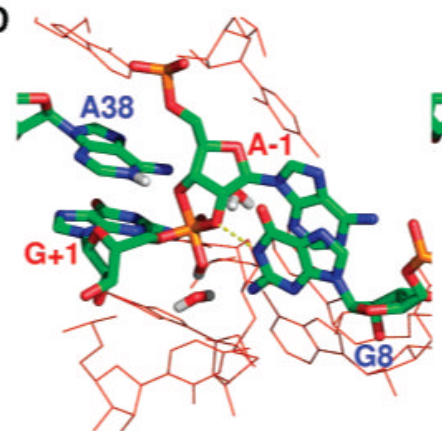

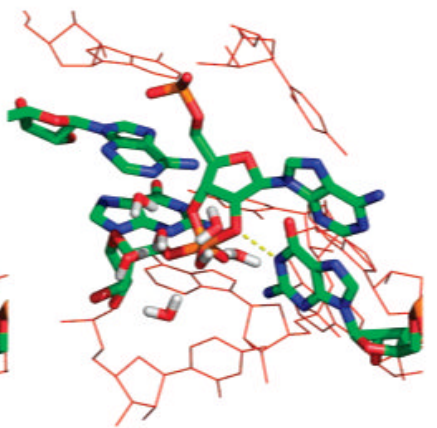

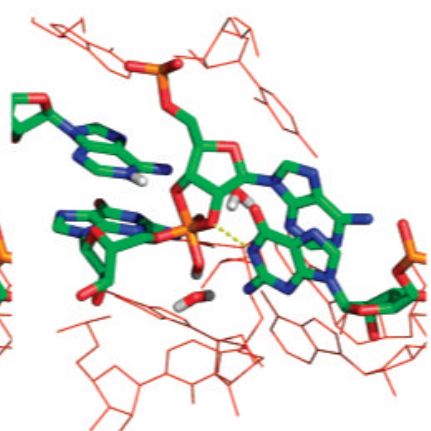

Figure 2.

Stereoview of active site snapshot of the monoprotic phosphorane intermediate from the inline monoanionic pathway via (A) $\mathrm{O}_{1 \mathrm{P}}$ atom and (B) $\mathrm{O}_{2 \mathrm{P}}$ atom, and the $\mathrm{A} 38(+)$ mediated monoanionic pathways via (C) $\mathrm{O}_{1 \mathrm{P}}$ atom and (D) $\mathrm{O}_{2 \mathrm{P}}$ atom. Water molecules that interact with nonbridging oxygens and the leaving group $\mathrm{O}_{5^{\prime}}$ are also displayed. 
A

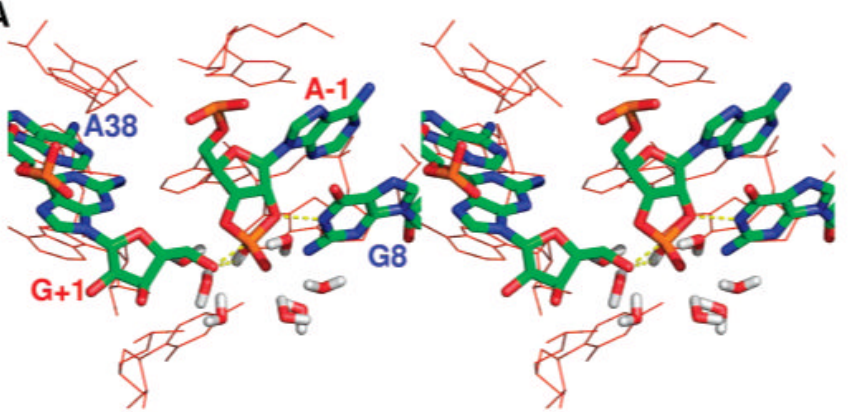

C

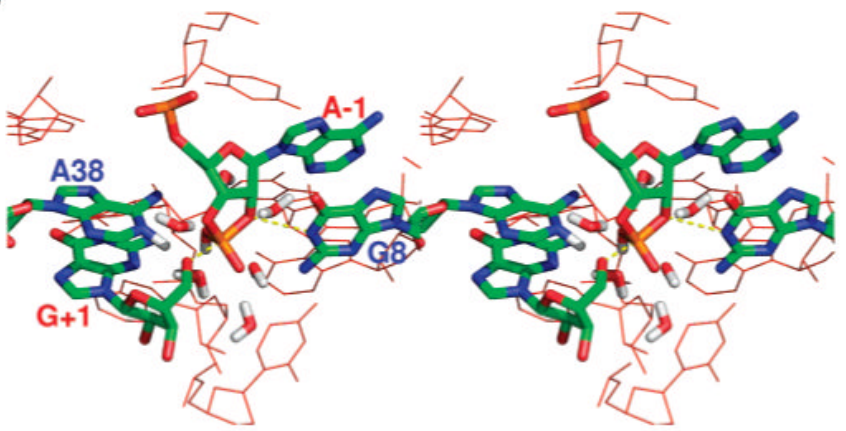

B
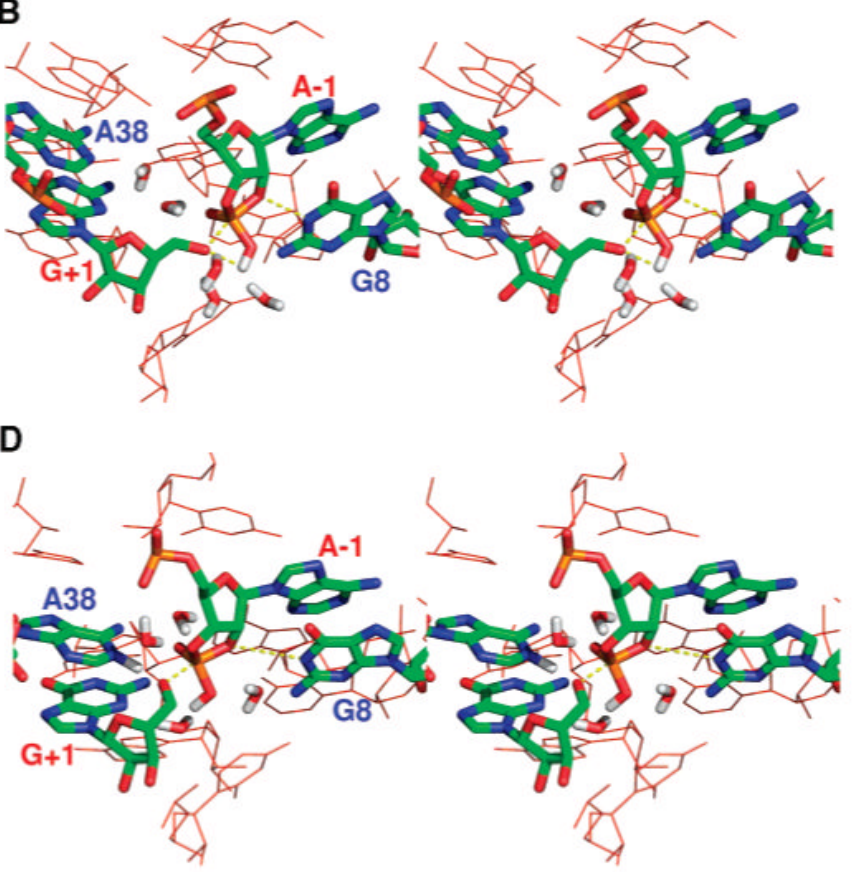

Figure 3.

Stereoview of active site snapshot at the transition state of the exocyclic cleavage step from the in-line monoanionic pathway via (A) $\mathrm{O}_{1 \mathrm{P}}$ atom and (B) $\mathrm{O}_{2 \mathrm{P}}$ atom, and the $\mathrm{A} 38(+)$ mediated monoanionic pathways via (C) $\mathrm{O}_{1 \mathrm{P}}$ atom and (D) $\mathrm{O}_{2 \mathrm{P}}$ atom. Water molecules that interact with nonbridging oxygens and the leaving group $\mathrm{O}_{5^{\prime}}$ are also displayed. 


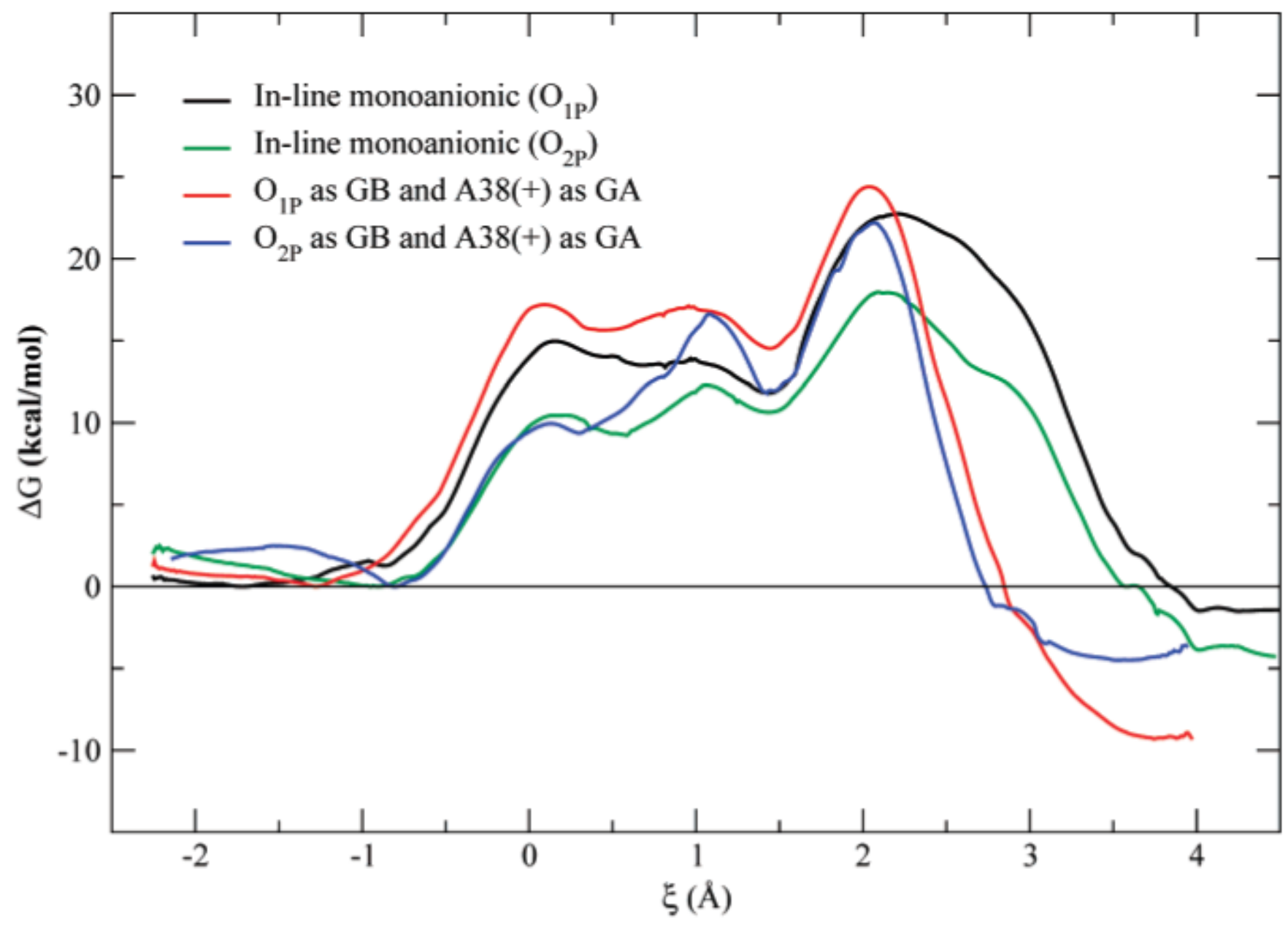

Figure 4.

Comparisons of 1-dimensional potentials of mean forces for the in-line monoanionic (black and green colored solid line) and A38(+) mediated reaction mechanisms (red and blue colored solid line). The reaction coordinate is defined in eqs 2 and 3 by following minimum PMF pathways for each separate 2-D PMF profiles. GB and GA are the general base and acid, respectively. 


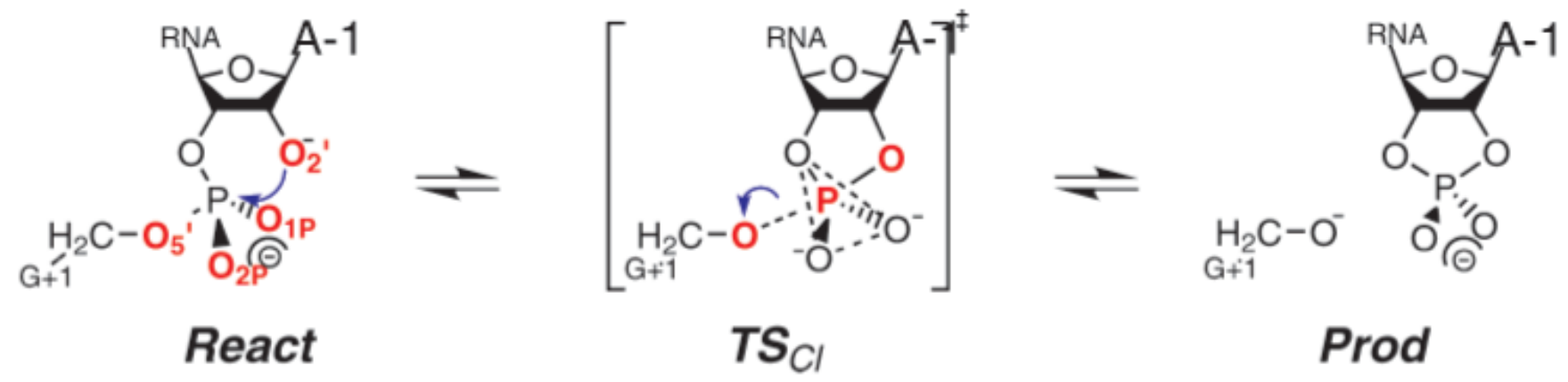

Scheme 1.

Scheme of the Dianionic Reaction Mechanism for the Self-Cleavage Catalyzed by Hairpin Ribozyme 


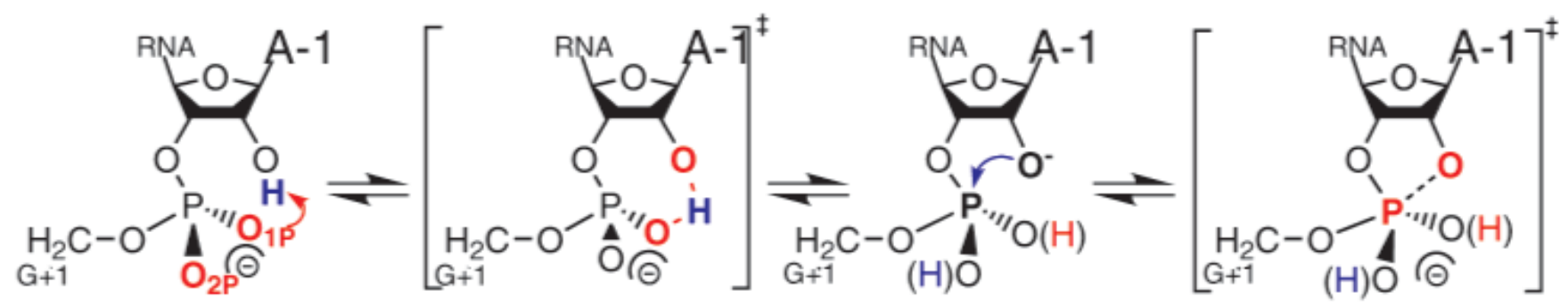

React

$T S_{P T 1}$

INT 1

$T S_{N u}$

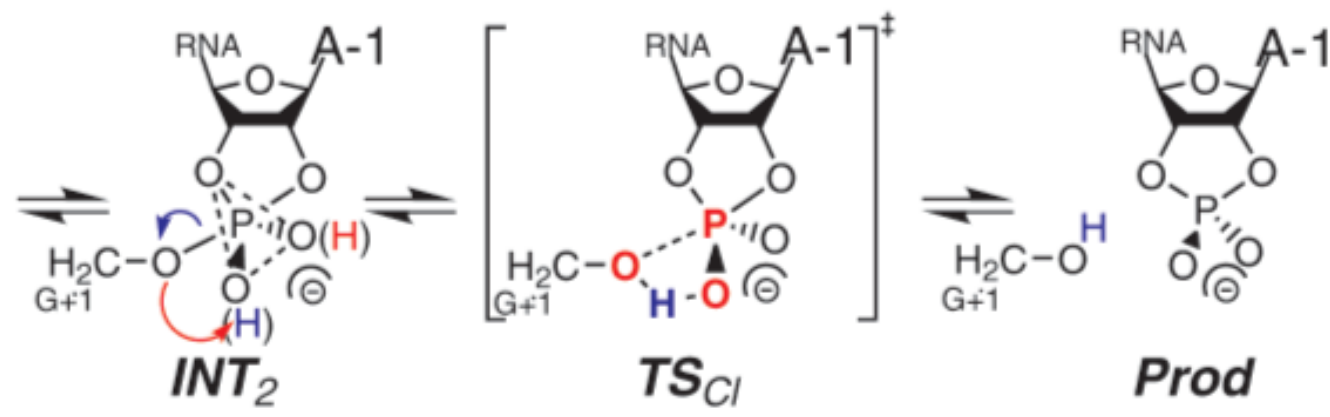

Scheme 2.

Scheme of the In-Line Monoanionic Reaction Mechanisms for the Self-Cleavage Catalyzed by Hairpin Ribozyme ${ }^{a}$

${ }^{a} \mathrm{O}_{1 \mathrm{P}}$ and $\mathrm{O}_{2} \mathrm{P}$ pathways are denoted as blue and red colored hydrogens in phosphorane intermediate, respectively. 


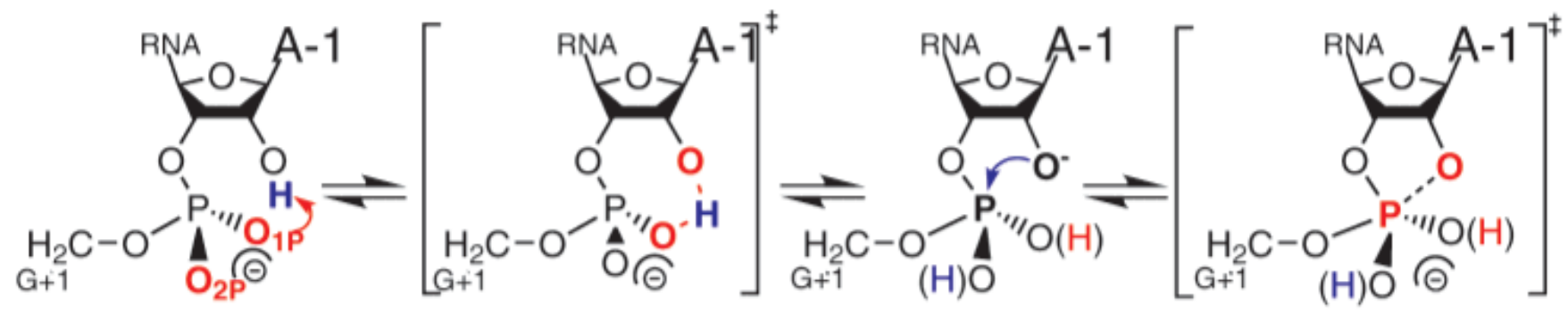

React

$T S_{P T 1}$

INT $_{1}$

$T S_{N u}$

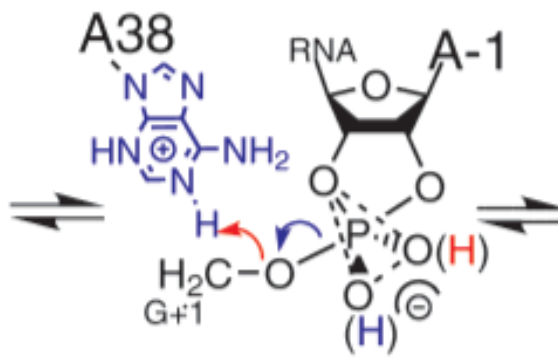

$I N T_{2}$

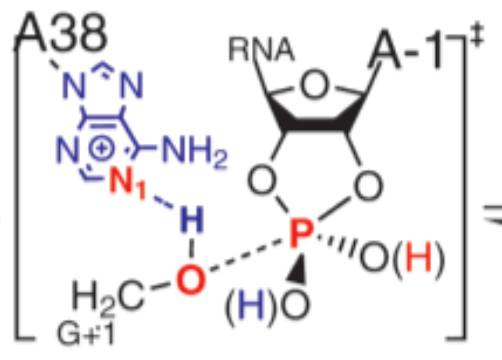

$\boldsymbol{T S}_{C I}$<smiles>C=CC=CCCO</smiles><smiles>C1CCCOCCC1</smiles>

Prod

Scheme 3.

Scheme of the A38 Mediated Monoanionic Reaction Mechanisms for the Self-Cleavage Catalyzed by Hairpin Ribozyme ${ }^{a}$

${ }^{a} \mathrm{O}_{1 \mathrm{P}}$ and $\mathrm{O}_{2 \mathrm{P}}$ pathways are denoted as blue and red colored hydrogens in phosphorane intermediate, respectively. 


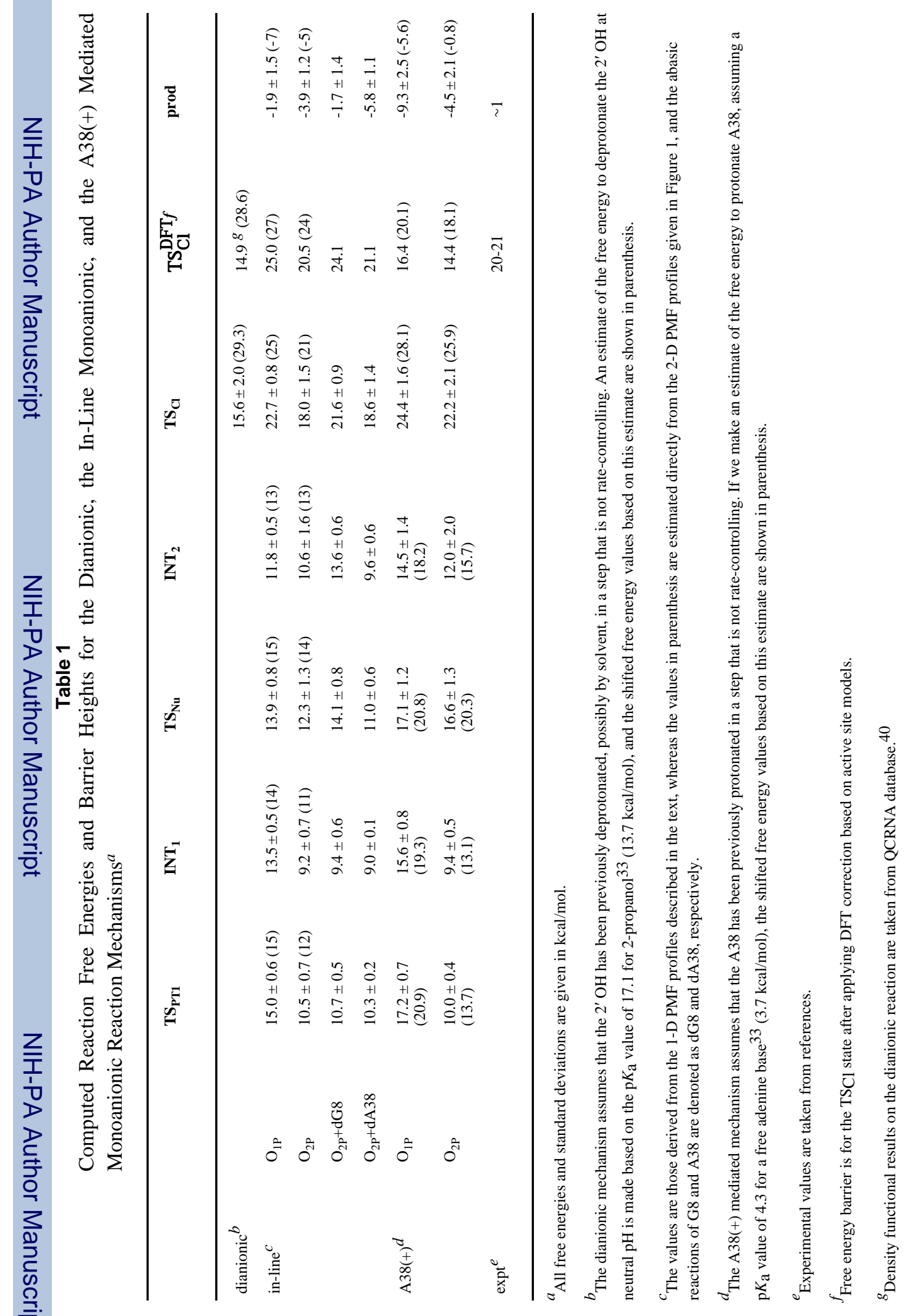


Nam et al.

Page 24

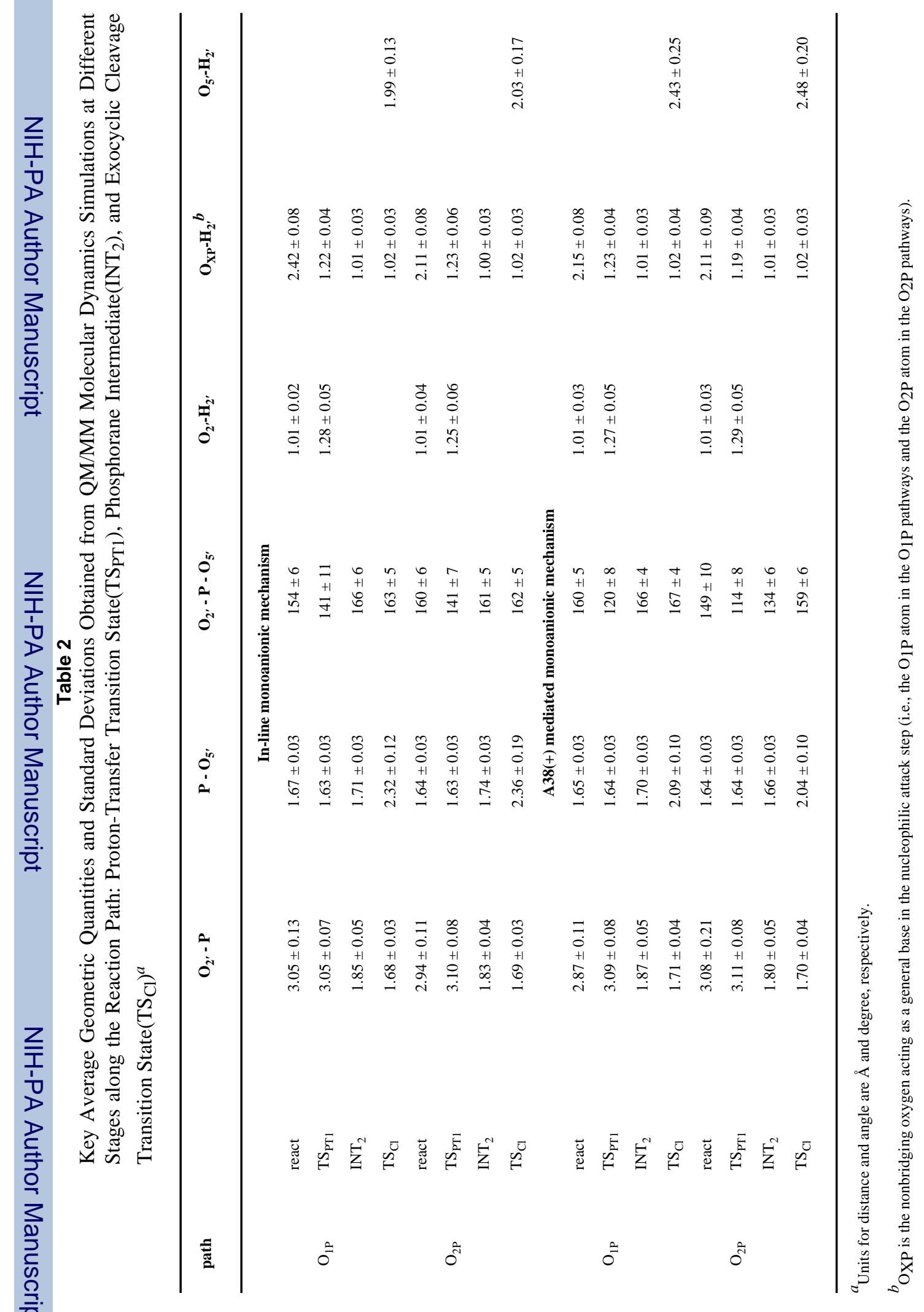

J Am Chem Soc. Author manuscript; available in PMC 2009 April 9. 


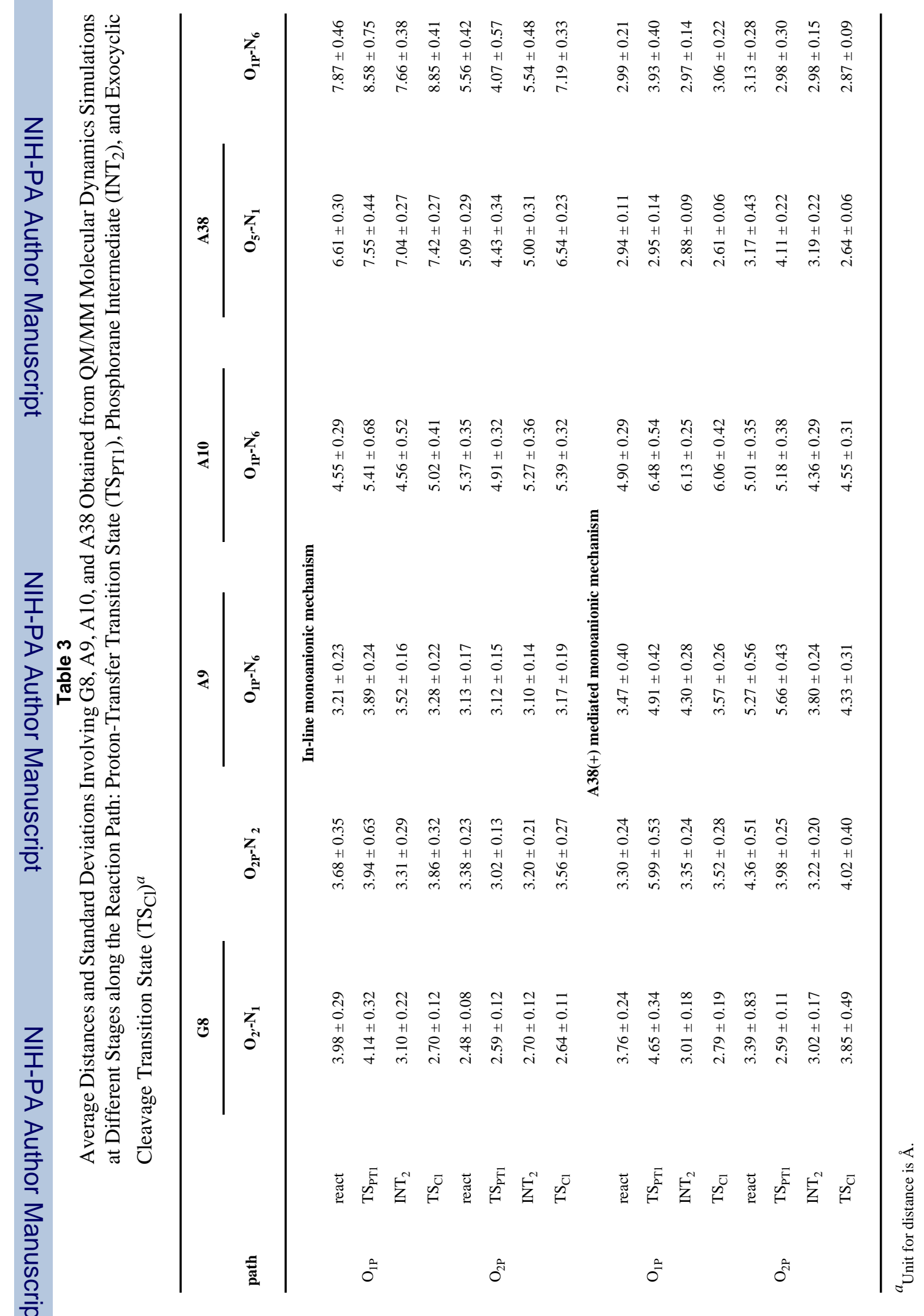




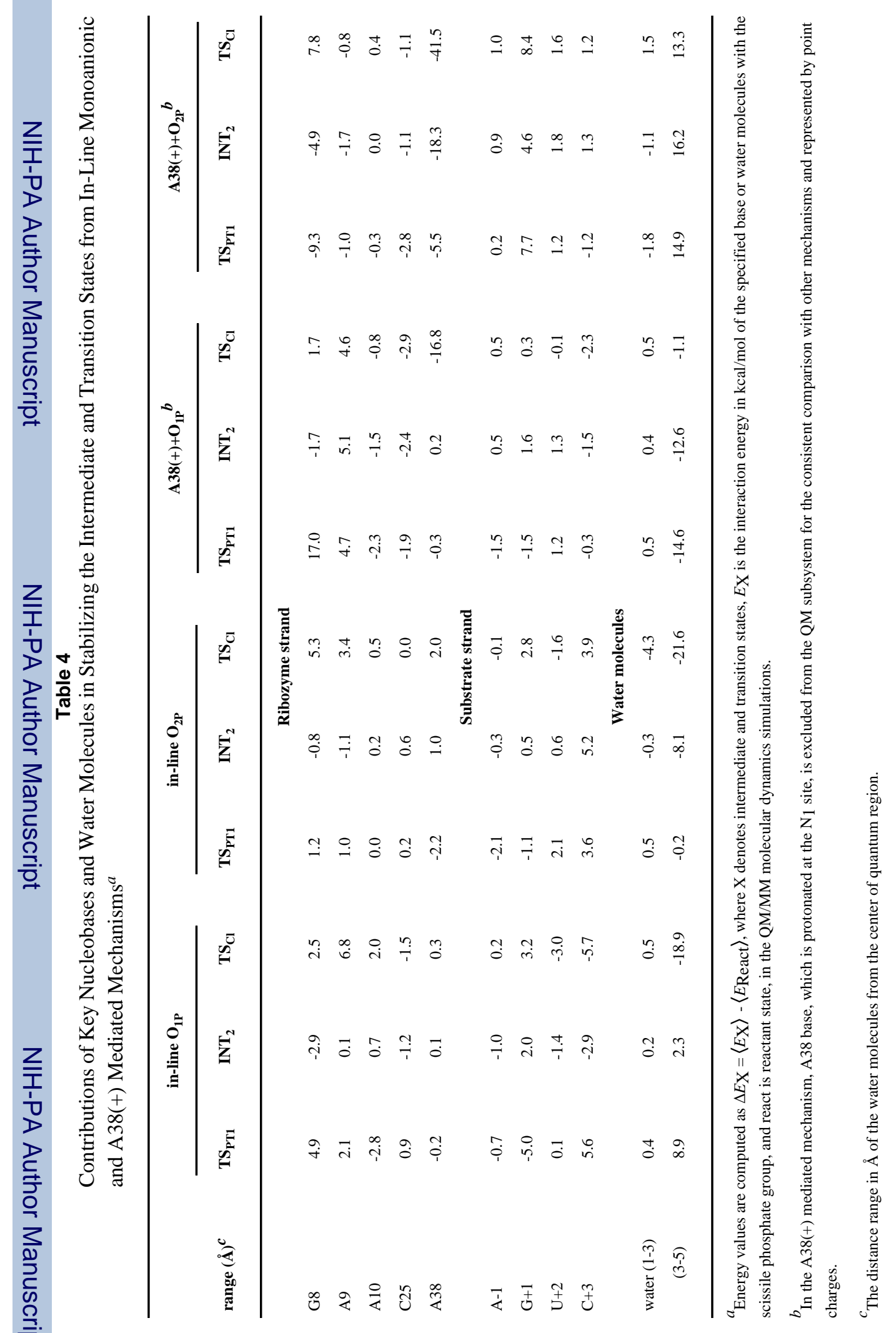

